\title{
Uterine and placental distribution of selected extracellular matrix (ECM) components in the dog
}

\author{
Felix R Graubner ${ }^{1}$, Alois Boos ${ }^{1}$, Selim Aslan², Ibrahim Kücükaslan ${ }^{3}$ and Mariusz P Kowalewski ${ }^{1}$ \\ ${ }^{1}$ Institute of Veterinary Anatomy, Vetsuisse Faculty, University of Zurich, Zurich, Switzerland, ${ }^{2}$ Department of \\ Obstetrics and Gynecology, Faculty of Veterinary Medicine, Near East University, Nicosia, North Cyprus, Turkey and \\ ${ }^{3}$ Department of Obstetrics and Gynecology, Faculty of Veterinary Medicine, Dicle University, Diyarbakir, Turkey
}

Correspondence should be addressed to M P Kowalewski; Email: kowalewski@vetanat.uzh.ch

\begin{abstract}
For many years, modifications of the uterine extracellular matrix (ECM) during gestation have not been considered as critical for successful canine (Canis lupus familiaris) pregnancy. However, previous reports indicated an effect of free-floating blastocysts on the composition of the uterine ECM. Here, the expression of selected genes involved in structural functions, cell-to-cell communication and inhibition of matrix metalloproteinases were targeted utilizing qPCR and immunohistochemistry. We found that canine freefloating embryos affect gene expression of FN1, ECM1 and TIMP4. This seems to be associated with modulation of trophoblast invasion, and proliferative and adhesive functions of the uterus. Although not modulated at the beginning of pregnancy, the decrease of structural ECM components (i.e. COL1, $-3,-4$ and LAMA2) from pre-implantation toward post-implantation at placentation sites appears to be associated with softening of the tissue in preparation for trophoblast invasion. The further decrease of these components at placentation sites at the time of prepartum luteolysis seems to be associated with preparation for the release of fetal membranes. Reflecting a high degree of communication, intercellular cell adhesion molecules are induced following placentation (Cx26) or increase gradually toward prepartum luteolysis $(C x 43)$. The spatio-temporal expression of TIMPs suggests their active involvement in modulating fetal invasiveness, and together with ECM1, they appear to protect deeper endometrial structures from trophoblast invasion. With this, the dog appears to be an interesting model for investigating placental functions in other species, e.g. in humans in which Placenta accreta appears to share several similarities with canine subinvolution of placental sites (SIPS). In summary, the canine uterine ECM is only moderately modified in early pregnancy, but undergoes vigorous reorganization processes in the uterus and placenta following implantation.

Reproduction (2018) 155 403-421
\end{abstract}

\section{Introduction}

Interactions between the canine (Canis lupus familiaris) uterus and the corpora lutea $(\mathrm{CL})$, and the interchange between the uterus and fetal trophoblast, represent remarkably unique mechanisms among mammalian species.

The bitch is a monoestric, non-seasonal breeder in which ovulation occurs spontaneously (Concannon 1993). As in other domestic animals, $C L$ are formed following ovulation, but in contrast to other species, in canine pregnancy, no placental steroid hormone synthesis arises (Hoffmann et al. 1994). Consequently, the increasing circulating steroid levels in both nonpregnant and pregnant bitches fully originate from the $\mathrm{CL}$ with luteal progesterone (P4) being responsible for the establishment and maintenance of pregnancy until term (Concannon et al. 1989). Due to the lack of luteolysis in the absence of pregnancy, peripheral P4 levels are almost identical in non-pregnant and pregnant bitches until shortly before parturition when prepartum luteolysis occurs signaling the onset of parturition (Concannon et al. 1989). Consequently, in contrast to livestock, in the dog, successful pregnancy does not depend on the inhibition of luteolysis to maintain the luteal life span and thereby embryo survival (Kowalewski et al. 2009, Gram et al. 2013, Kowalewski 2014). In other domestic animal species, pre-attachment embryos transmit signals needed to extend $\mathrm{CL}$ function (Niswender et al. 2000, Bazer et al. 2010, Bazer 2015), referred to as 'maternal recognition of pregnancy' (Short 1969). This embryo-maternal communication synchronizes blastocyst development and uterine receptivity in a complex series of molecular and cellular mechanisms (Seshagiri et al. 2009, Paidas et al. 2010). In some species, e.g.- in rodents or primates, the uterine changes result in decidua formation and are therefore very pronounced. In primates, decidualization takes place even in the absence of embryos, while in rodents, it is induced by their presence (reviewed in Cha et al. 2012). In early pregnancy, the uterine extracellular matrix (ECM) influences trophoblast invasion (Johnson et al. 
2003) and remodeling of the decidua (Damsky et al. 1993, Lala \& Nandi 2016, Smith et al. 2016). The formation of decidua, e.g.- in mice, is associated with clearing of hyaluronic acid from the uterine stroma (Brown \& Papaioannou 1992). In addition, in vitro studies demonstrate that decidualizing stromal cells of mouse and human origin produce ECM products such as basal lamina-like materials (Wewer et al. 1985, 1986, Kisalus et al. 1987).

Despite the absence of an antiluteolytic signal at the beginning of pregnancy, in the dog synchronization between blastocyst development and uterine preparation for implantation is also essential for healthy pregnancy. Thus, in dogs and other carnivores, decidualization also takes place and is associated with implantation and placenta formation (Wislocki \& Dempsey 1946, Dempsey \& Wislocki 1956, Kautz et al. 2014, Graubner et al. 2017b). In accordance with the aforementioned in vitro decidualization studies with mouse and human cells, canine uterine cells can also be decidualized in vitro. Their response to a decidual stimulus (i.e.- increased secretory and proliferative activity) provides evidence that also in dogs uterine ECM modulation during decidualization occurs (Kautz et al. 2015). Furthermore, functional genomics studies imply that in vivo canine free-floating embryos transmit signals to the uterus and discretely, i.e., without clearly visible morphological changes, affect uterine ECM composition at the early stage of pregnancy (Graubner et al. 2017a). Indicating the beginning of canine decidualization, these embryo-derived signals control the expression of uterine biochemical markers of decidualization (Kautz et al. 2014). The first morphological signs of decidualization are found later, commencing with attachment of the trophoblast (Graubner et al. 2017b). Ultimately, the uterine modifications become advanced and maternal-derived decidual cells are formed as an indispensable component of the endotheliochorial placenta in the dog. Decidual cells are needed for successful pregnancy since they are the only cells in the canine placenta expressing the nuclear P4 receptor (PGR) (Vermeirsch et al. 2000, Kowalewski et al. 2010). Additionally, these cells and maternal endothelium can resist trophoblast digestion. Adequate embryomaternal contacts between the trophoblast and maternal decidual cells, all embedded in the ECM components, are important for the maintenance and termination of pregnancy. Thus, withdrawal of P4 from decidual cells will interfere with their physiological function and lead to abortion or preterm parturition (Kowalewski et al. 2010). ECM components appear to be involved here in feto-maternal communication leading to the luteolytic cascade, expulsion of fetuses and fetal membranes. Disturbances in embryo-maternal communication may result in clinical conditions like subinvolution of placental sites (SIPS), resembling placenta accreta in humans characterized by excessive trophoblast invasion.
Formation of the endotheliochorial placenta in the dog and other carnivores, indeed represents a unique type of placentation, with strong, but yet restricted, invasion. So far, little attention has been paid to uterine function in dogs during pregnancy, resulting in limited knowledge about its possible involvement in the establishment, maintenance and termination of pregnancy.

Because of this lack of information, driven by the hypothesis that ECM compounds are strongly modified throughout canine gestation, this study focused on the localization (utilizing immunohistochemistry (IHC)) and expression (using semi-quantitative TaqMan PCR) of several ECM proteins in the canine uterus. Selected stages of the reproductive cycle were considered, starting with morpho-functional modifications induced by the presence of pre-attachment embryos, through implantation, early and late placentation, until prepartum luteolysis. A variety of different factors collectively represent the term ECM. Here, the uterine localization and expression of ECM components with structural and adhesive functions were investigated (e.g.- collagen (COL) 1, -3 and -4, alpha smooth muscle actin (aSMA) and fibronectin (FN) 1). Additionally, proteins of the basal lamina, proteins involved in cellto-cell communication and proteins involved in the inhibition of matrix metalloproteinases were targeted (e.g.- connexin (Cx) 26 and -43, laminin alpha (LAMA) 2, extracellular matrix protein 1 (ECM1) and tissue inhibitor of metalloproteinases (TIMP) 2 and -4).

\section{Materials and methods}

\section{Sample collection}

In the present study, tissue material from 31 crossbred healthy bitches aged 2-8 years was used. Animals were randomly assigned to the following groups: (1) early pregnant (preattachment days 10-12; $n=10)$; (2) corresponding nonpregnant controls $(n=8)$; (3) early post-implantation (days 18-25 of pregnancy; $n=5$ ); (4) mid-gestation (days 35-40 of pregnancy; $n=5)$ and (5) prepartum luteolysis $(n=3)$.

Estrus detection was performed by cytological evaluation of vaginal smears and regular measurements of $\mathrm{P} 4$ concentrations every 2-3 days starting with the proestrous bleeding. The day when P4 blood levels increased $>5 \mathrm{ng} / \mathrm{mL}$ for the first time was determined as the day of ovulation. Considering the peculiar need for canine oocyte maturation within the oviduct (on average $2-3$ days after ovulation), bitches were mated 2 days after ovulation (defined as day 0 of gestation). Tissue collection was performed through routine ovariohysterectomy (OHE). In the early pregnant group (group 1), OHE was performed between days 10 and 12 of gestation. Pregnancy was confirmed by flushing free-floating (i.e., pre-attachment) embryos. Dogs negative for embryo flushing were allotted to group 2 (corresponding non-pregnant control at day 10-12 of the luteal phase). The prepartum luteolysis takes place in the dog $12-24 \mathrm{~h}$ before any visible physiological signs of parturition. Therefore, for group 5, blood samples were collected every $6 \mathrm{~h}$ 
starting on day 58 of pregnancy. When circulating P4 levels continued to decrease below $2-3 \mathrm{ng} / \mathrm{mL}$ in 3 consecutive measurements, indicating the prepartum luteolysis, samples were collected. Tissue collection in groups 1 and 2 consisted of uterine cross-sections (the whole thickness of the uterine wall). For groups 3-5, sampling included utero-placental crosssections (Ut-PI; the whole thickness of the uterine wall, i.e., uterus with adjacent placenta). Additionally, for groups 3 and 4 inter-placental uterine cross-sections (inter-Pl; full thickness like groups 1 and 2) were collected. No inter-PI samples were available from the natural luteolysis group of dogs (group 5).

For semi-quantitative real-time PCR, cellular RNA was stabilized by immersing the samples for $24 \mathrm{~h}$ at $4{ }^{\circ} \mathrm{C}$ in RNAlater (Ambion Biotechnologie $\mathrm{GmbH}$, Wiesbaden, Germany); prolonged storage was at $-80^{\circ} \mathrm{C}$. For immunohistochemistry (IHC) studies, tissues were fixed for $24 \mathrm{~h}$ in $10 \%$ neutral phosphate-buffered formalin at $4^{\circ} \mathrm{C}$, and subsequently washed for 1 week with PBS (phosphate-buffered saline) and embedded in paraffin wax. For additional information about tissue sampling and processing procedures, see previous reports (Kowalewski et al. 2010, Gram et al. 2013, Kautz et al. 2014). All uterine tissue samples were used for semi-quantitative realtime PCR, while 3 randomly chosen samples from each group were used for IHC.

All experimental procedures were carried out in accordance with animal welfare legislation and approved by the respective authorities of the University of Ankara (permits no. 2006/06 and 2008-25-124) Ankara, Turkey and Justus-Liebig University Giessen (permit no. II 25.3-19c20-15c Gl 18/14 and VIG319c-20/15c Gl 18, 14) Giessen, Germany.

\section{RNA isolation, reverse transcription (RT), semi- quantitative (TaqMan) PCR and evaluation of data}

Semi-quantitative TaqMan PCR was performed on total RNA isolated from all dogs. For this, TRIzol reagent (Invitrogen) was used according to the manufacturer's instructions. From each sample $10 \mathrm{ng}$ total RNA were used for RQ1 RNAse-free DNAse treatment (Promega). The RT reaction was performed according to the manufacturer's instructions with the HighCapacity cDNA Reverse Transcription Kit including RNase Inhibitor (Applied Biosystems from Thermo Fisher Scientific). Following this, amplification of cDNA was performed with the TaqManPreAmp Master Mix Kit (Applied Biosystems) according to the supplier's protocol. Detailed information about the TaqMan PCR procedure has been previously published (Kowalewski et al. 2006b, 2011, Kautz et al. 2015). In short, reactions were run in duplicates with the Fast Start Universal Probe Master (ROX) (Roche Diagnostics AG) in an automated fluorometer (ABI PRISM 7500 Sequence Detection System, Applied Biosystems). For negative controls, the so-called RT-minus control was used to check for potential genomic DNA contamination. Additional controls consisted of running experiments with autoclaved water instead of cDNA (no-template control) (Kowalewski et al. 2006b, 2011). If canine-specific TaqMan systems were not available commercially, Primer Express Software v2.0 (Applied Biosystems) was used to select primers and probes, which were purchased from Microsynth, Balgach, Switzerland.
TaqMan probes were designed with 6-FAM- and TAMRAlabels. For a list of self-designed primer sequences and TaqMan systems refer Table 1 . The self-designed expression assays were validated by the CT slope method, which tests the TaqMan efficiency at different quantities of the targeted RNA as previously described (Kowalewski et al. 2011). The reaction efficiency for all self-designed assays was approximately $100 \%$. Three reference genes, GAPDH, Cyclophilin $A$ (PPIA) and $A C T I N-B$, were used for normalization to ensure homogeneity of variances. The following canine-specific TaqMan Gene Expression Assays were ordered from Applied Biosystems: PPIA (Prod. No. Cf03986523-gH); ACTIN-B (Prod. No. Cf03023880_g1), collagen type 1, alpha 1 (COL1A1) (Prod. No. Cf02741575_mH); COL type 3, alpha 1 (COL3A1) (Prod. No. Cf02631366_m1); COL type 4, alpha 1 (COL4A1) (Prod. No. Cf02696157_mH). For relative quantification, the comparative $C T$ method $(\Delta \Delta \mathrm{CT}$ method) was applied as previously described (Kowalewski et al. 2010, 2011). The sample with the lowest expression was used as a calibrator.

Statistical differences between the non-pregnant and early pregnant group (groups 1 and 2) were determined by an unpaired, two-tailed Student's $t$-test; a $P$ value $<0.05$ was considered as statistically significant. When target gene expression was compared in more than 2 observational groups (time-dependent expression at selected time points during pregnancy), a parametric one-way ANOVA was applied. In the case of $P<0.05$, the Tukey-Kramer multiple comparisons post-test was performed. Statistical assumptions, such as normality and equality of variances were tested prior to applying the t-test or ANOVA. All analyses were performed with GraphPad 3.06 software (GraphPad Software). Numerical data are presented as geometric means $\mathrm{Xg} \pm$ geometric standard deviation (s.D.).

\section{Immunohistochemistry}

Standard immunohistochemistry (IHC) was performed to identify the localization of several ECM proteins. Detailed information about our indirect immunoperoxidase method has been published previously (Kowalewski et al. 2006a,b). In short, following embedding in paraffin, tissues were sectioned into $2-3 \mu \mathrm{m}$ thickness, mounted onto SuperFrost microscope slides (Menzel-Glaser, Braunschweig, Germany). Following de-paraffinization using xylene and rehydratation in an ethanol series, antigen retrieval was performed using either heatinduced epitope retrieval (HIER) or protease-induced epitope retrieval (PIER). HIER was performed in a microwave oven at $560 \mathrm{~W}$ for $15 \mathrm{~min}$ in $10 \mathrm{mM}$ citrate buffer with $\mathrm{pH}$ 6.0. PIER was performed using $0.25 \%$ pepsin (P7000 Sigma-Aldrich Chemie $\mathrm{GmbH}$ ) in $10 \mathrm{mM} \mathrm{HCl}$ at $37^{\circ} \mathrm{C}$. The duration of PIER varied from 5 min to 90 min depending on the antibody (for detailed information see Table 2). Following antigen retrieval, sections were treated with $0.3 \%$ hydrogen peroxide in methanol for $30 \mathrm{~min}$ to block endogenous peroxidases. After that, blocking was performed with $10 \%$ normal serum from the same species in which the secondary antibody was produced, and overlaid with primary antibodies overnight at $4^{\circ} \mathrm{C}$. For negative controls, non-immune IgGs of the same species instead of the primary 


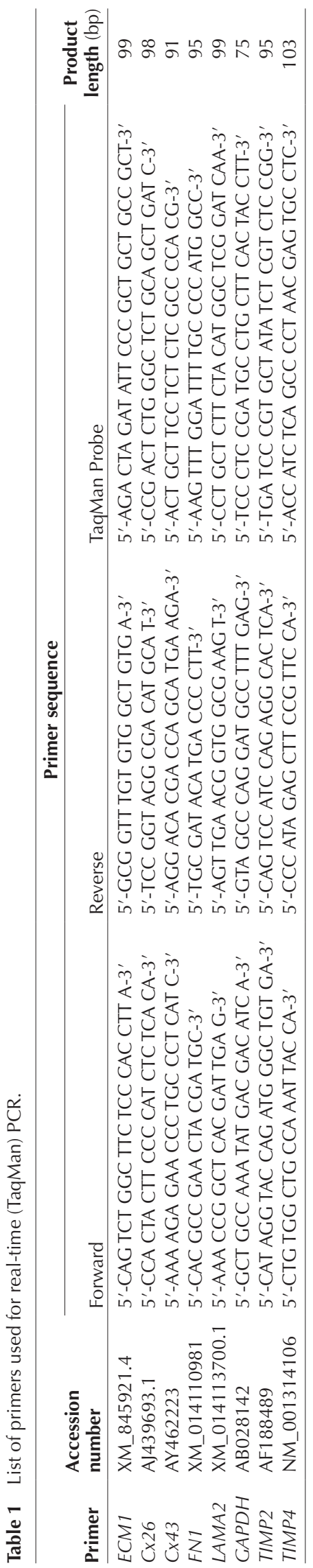

antibody at the same protein concentration as for the primary antibody were used (isotype controls).

Following incubation with the primary antibody, sections were washed with $\mathrm{IHC}$ buffer/0.3\% Triton $\mathrm{X} \mathrm{pH} \mathrm{7.2-7.4}$ $\left(0.8 \mathrm{mM} \mathrm{Na}_{2} \mathrm{HPO}_{4}, 1.74 \mathrm{mM} \mathrm{KH} \mathrm{PO}_{4}, 2.68 \mathrm{mM} \mathrm{KCl}, 137 \mathrm{mM}\right.$ $\mathrm{NaCl}$ ), and incubated with biotin-labeled secondary antibodies at 1:100 dilution. Next, the signals were enhanced using the Vectastain ABC Kit (Vector Laboratories, Inc., Burlingame, CA, USA) for $30 \mathrm{~min}$, and immune reactions were visualized with the Liquid DAB+ substrate kit (Dako Schweiz AG, Baar, $\mathrm{CH}$ ). Counter-staining was performed with hematoxylin. Next, dehydration was performed in an ethanol series and xylene, and mounted using Histokit (Assistant, Osterode, Germany). Detailed information about commercially available primary and secondary antibodies, antigen retrieval and concentrations is given in Table 2. All groups within one experiment were simultaneously stained with Liquid DAB + substrate kit (Dako) for the same target using the same development time.

All slides were qualitatively evaluated for localization of the respective target protein and representative pictures were taken. Two researchers with good experience in canine uterine and placental histology evaluated the signals of target genes independently, using an ordinal system of none (-), weak $(+/-)$, strong $(+)$ and very strong (++) present (Fig. 5).

To identify the specific localization of TIMP2 und TIMP4 in the canine placenta, 4 consecutive slides $(2-3 \mu \mathrm{m}$ thickness) were prepared from placenta in the prepartum luteolysis group. Each consecutive slide was stained with a different primary antibody (TIMP2, TIMP4, vimentin (VIM), pancytokeratin (pan-CYT)). Vimentin was used as a marker of mesenchymal cells in order to differentiate between different placental cellular compartments. It stains positively for decidual cells, endothelial cells and fibroblasts. Cytokeratin served as a marker for epithelial cells, staining positively in fetal trophoblast. The staining and evaluation procedures were as described earlier.

\section{Results}

mRNA expression of ECM proteins in canine uterus, inter-PI and Ut-PI compartments at selected time points during pregnancy and prepartum luteolysis

In all samples, the mRNA expression of ECM proteins, cell adhesion molecules and modulators of ECM was detectable by applying semi-quantitative (TaqMan) PCR.

To evaluate embryo-induced changes in the uterus, a pairwise comparison between non-pregnant and early pregnant (pre-attachment) bitches was performed. In this contrast, $F N 1$ was significantly suppressed $(P=0.01)$ by the presence of embryos during early pregnancy (preattachment), in contrast to increased ECM1 and TIMP4 expression ( $P=0.01$ ) (Fig. 1). COL1, COL3, COL4, Cx26 and -43 were not affected at the beginning of early pregnancy $(P>0.05$, not shown). Effects of the presence of embryos on LAMA2 and TIMP2 mRNA expression in the pre-implantation uterus were investigated previously (Graubner et al. 2017a) and were, therefore, excluded from the present study. 
Table 2 List of primary and secondary antibodies used for indirect immunohistochemistry (IHC).

\begin{tabular}{|c|c|c|c|c|}
\hline Antibody & Company & Reference number & Antigen retrieval & Dilution \\
\hline Collagen I (COL1) & Rockland & 31680 & PIER $60 \mathrm{~min}$ & $1: 800$ \\
\hline Collagen III (COL3) & Quartett & 292302 & PIER $45 \mathrm{~min}$ & $1: 200$ \\
\hline Collagen IV (COL4) & Quartett & 250424 & PIER $60 \mathrm{~min}$ & $1: 500$ \\
\hline Laminin 2 alpha (LAMA2) & Bioss Antibodies & bs-8561R & PIER $90 \mathrm{~min}$ & $1: 300$ \\
\hline Fibronectin 1 (FN1) & Novus Biologicals & NBP1-91258 & PIER $30 \mathrm{~min}$ & $1: 300$ \\
\hline alpha Smooth muscle actin (aSMA) & Dako & M0851 & HIER & $1: 100$ \\
\hline Connexin 26 (Cx26) & Thermo Fisher & QC215178 & PIER 5 min & $1: 200$ \\
\hline Connexin $43(\mathrm{C} \times 43)$ & Abcam & AB11370 & PIER $15 \mathrm{~min}$ & $1: 750$ \\
\hline Tissue inhibitor of matrix metalloproteinase-2 (TIMP2) & Merck Millipore & AB2965 & HIER & 1:1500 \\
\hline Tissue inhibitor of matrix metalloproteinase-4 (TIMP4) & LifeSpan Biosciences & LS-C116809 & HIER & $1: 750$ \\
\hline Anti-vimentin clone vim3B4 (VIM) & Dako & M7020 & HIER & $1: 100$ \\
\hline Anti-cytokeratin (pan-CYT) & Dako & Z0622 & HIER & $1: 700$ \\
\hline Extracellular matrix protein 1 (ECM1) & Proteintech & 11521-1-AP & HIER & $1: 200$ \\
\hline Biotinylated goat anti-rabbit $\lg G(\mathrm{H}+\mathrm{L})$ & Vector Laboratories & BA-1000 & - & $1: 100$ \\
\hline Biotinylated horse anti-mouse $\operatorname{lgG}(\mathrm{H}+\mathrm{L})$ & Vector Laboratories & BA-2000 & - & $1: 100$ \\
\hline
\end{tabular}

HIER, heat-initiated epitope retrieval; PIER, protease-initiated epitope retrieval.

Next, the uterine pre-implantation stage was compared to inter-PI sites and to the Ut-PI compartments from different stages of pregnancy (i.e., post-implantation, mid-gestation and prepartum luteolysis). In inter-Pl sites, uterine gene expression of ECM1 was significantly upregulated at mid-gestation compared with pre- and post-implantation $(P<0.001)$; it did not differ at earlier stages of pregnancy $(P>0.05)$, i.e., pre- and postimplantation (Fig. 2). The Ut-Pl compartments showed increased expression of the ECM1 gene in the prepartum luteolysis group compared with pre-implantation uterus and Ut-PI sites at early post-implantation stage $(P<0.001$ and $P<0.01$, respectively (Fig. 2 )).

The uterine expression of all three major collagens, COL1, COL3 and COL4, showed highest mRNA abundance at mid-gestation compared with either preimplantation $(P<0.05$ for COL1, $P<0.01$ for COL3 and $P<0.001$ for $C O L 4)$ or post-implantation $(P<0.05$ for COL1 and COL4). Whereas COL1 and COL4 did not differ between pre-implantation and post-implantation, COL3 was higher in the early post-implantation group
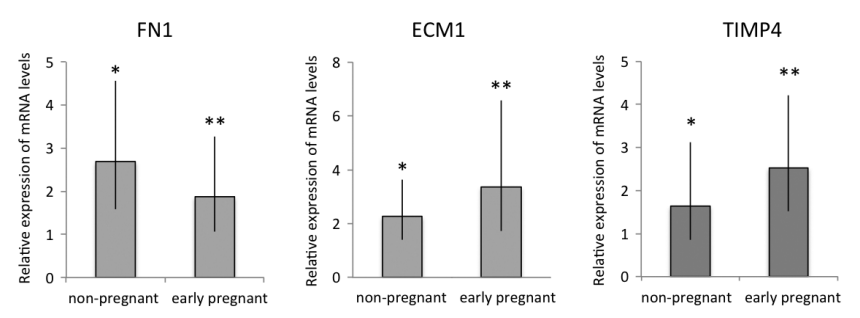

Figure 1 Expression of selected extracellular matrix (ECM) genes in the canine pre-implantation uterus (days 10-12 of pregnancy) affected by the presence of free-floating embryos, compared with gene expression in their non-pregnant counterparts as determined by Real-Time (TaqMan) PCR. FN1, fibronectin 1; ECM1, extracellular matrix protein 1; TIMP4, tissue inhibitor of metalloproteinases 4. An unpaired, two-tailed Student's $t$-test was applied. $P<0.05$ was defined as significant. Bars with different asterisks differ at $P=0.01$.

Numerical data are presented as geometric means $\mathrm{Xg} \pm$ geometric standard deviation (S.D.).
$(P<0.05)$ (Fig. 2). As for Ut-PI compartments, early implantation was associated with suppression of COL1 and COL3 levels $(P<0.001$ for COL1 and $P<0.05$ for COL3). Whereas they did not differ from postimplantation to mid-gestation, further suppression of both COLs mRNA expression was observed at prepartum luteolysis $(P<0.001$ and $P<0.01$ when compared with mid-gestation for COL1 and COL3, respectively) (Fig. 2). In contrast, the expression of COL4 in the Ut-PI comparison was unaffected at all examined stages of pregnancy $(P>0.05)$.

FN1 showed similar distribution patterns at inter-PI sites as COL1, COL3 and COL4. Following a more or less stable expression at inter-Pl at early gestation (i.e., during pre-implantation and post-implantation), its uterine mRNA levels were highest at mid-gestation compared with previous gestational stages $(P<0.05$ and $P<0.001$ for pre-implantation and post-implantation, respectively) (Fig. 3). At placentation sites (Ut-PI compartments), the prepartum luteolysis was associated with downregulation of FN1 compared with midgestation $(P<0.001)$ (Fig. 3).

The uterine mRNA levels of LAMA2 were not significantly changed $(P>0.05)$ during pre-implantation and post-implantation at the inter-PI sites, but decreased thereafter, from post-implantation to mid-gestation $(P<0.001)$ (Fig. 3). LAMA2 was strongly modulated at implantation sites, decreasing at Ut-Pl following early implantation $(P<0.001)$, but it was not further changed toward prepartum luteolysis (Fig. 3).

The uterine levels of Cx26 were lowest at preimplantation. They increased, however, significantly $(P<0.001)$ at inter-PI sites, showing the highest mRNA abundance post implantation (Fig. 3). Although apparently decreased at mid-gestation, Cx26 levels were still more highly represented at mid-gestation compared to pre-implantation $(P<0.001)$. When compared with $\mathrm{Ut}-\mathrm{Pl}$, the expression of $\mathrm{C} \times 26$ was also significantly increased at implantation sites $(P<0.001)$ and maintained 

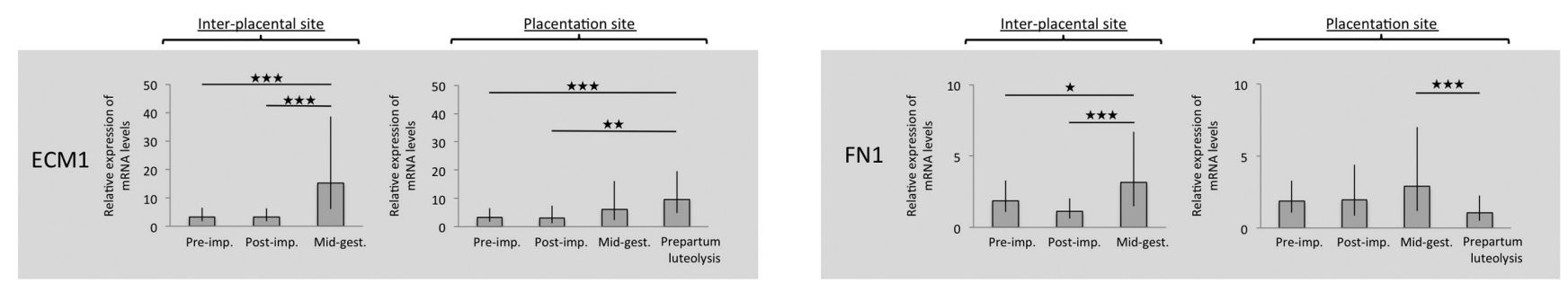
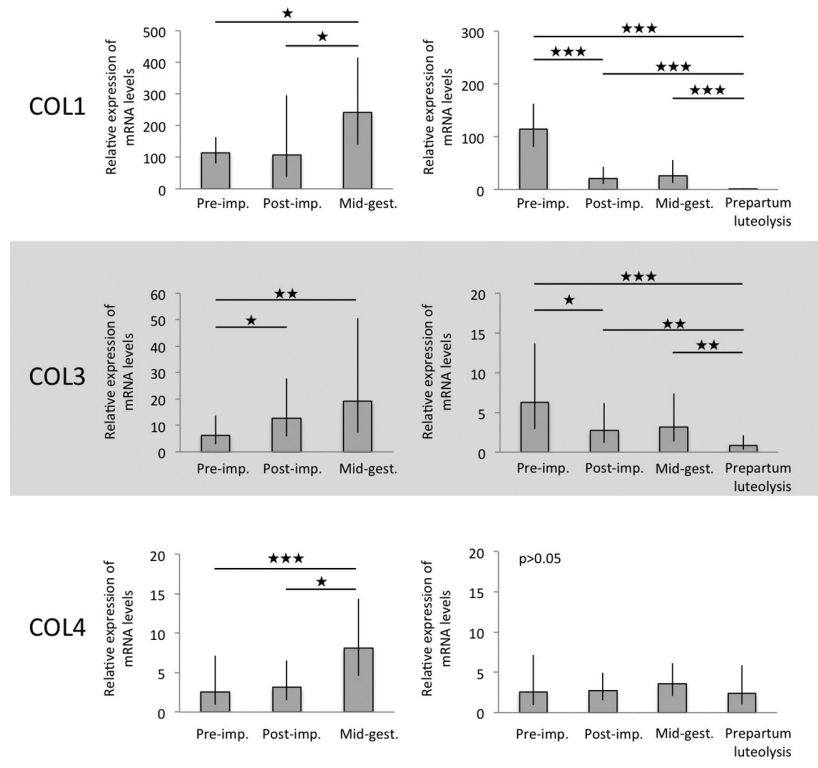

Figure 2 Expression of extracellular matrix protein 1 (ECM1), collagen $(C O L) 1,-3$ and -4 as determined by Real-Time (TaqMan) PCR in the canine uterus during different times of pregnancy. Two comparisons are presented for each gene: First, the pre-implantation (pre-imp.) stage was compared to the inter-placental sites during postimplantation (post-imp.) and mid-gestation (mid-gest.), and next to the utero-placental compartments (placentation sites) of postimplantation (post-imp.), mid-gestation (mid-gest.) and prepartum luteolysis. Asterisks indicate $\star P<0.05, \star \star P<0.01, \star \star \star P<0.001$. Numerical data are presented as geometric means $\mathrm{Xg} \pm$ geometric standard deviation (s.D.).

its high mRNA levels until mid-gestation. The decrease toward prepartum luteolysis was significant compared with Ut-Pl during post-implantation and mid-gestation $(P<0.001$ and $P<0.001$, respectively) (Fig. 3).

Uterine expression of the $\mathrm{C} x 43$ gene did not differ significantly at inter-PI sites $(P>0.05)$ (Fig. 3). It was, however, significantly modulated in Ut-PI compartments. Thus, implantation was associated with suppression of $\mathrm{C} \times 43$ expression at placentation sites compared with the pre-implantation uterus $(P<0.05)$. This expression continued, however, to increase at Ut-PI gradually toward prepartum luteolysis, showing significant differences from post-implantation toward mid-gestation $(P<0.05)$ and from mid-gestation to prepartum luteolysis $(P<0.05)$.

As for other genes, i.e., FN1, COL1, $-3,-4$, the uterine mRNA encoding for TIMP2 was highest at mid-gestation $(P<0.01$ and $P<0.001$ compared with pre-implantation
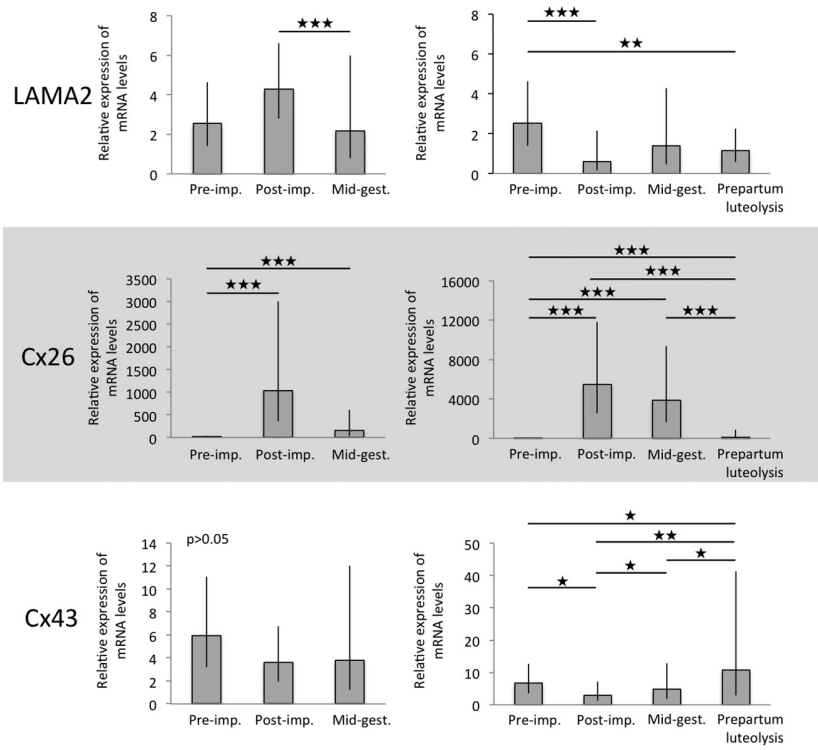

Figure 3 Expression of fibronectin 1 (FN1), laminin alpha 2 (LAMA2), connexin (CX) 26 and -43 as determined by Real-Time (TaqMan) PCR in canine uterus during different times of pregnancy. Two comparisons are presented for each gene: first, the pre-implantation (pre-imp.) stage was compared to inter-placental sites during post-implantation (post-imp.) and mid-gestation (mid-gest.), and next to the utero-placental compartments (placentation sites) of postimplantation (post-imp.), mid-gestation (mid-gest.) and prepartum luteolysis. Asterisks differ at $\star P<0.05, \star P<0.01, \star \star \star P<0.001$.

Numerical data are presented as geometric means $\mathrm{Xg} \pm$ geometric standard deviation (s.D.).

and post-implantation, respectively (Fig. 4). TIMP4 mRNA was already strongly induced at inter-PI after implantation $(P<0.001)$ and maintained its high levels through mid-gestation (Fig. 4). At placentation sites, both TIMP2 and TIMP4 were strongly modulated and showed a gradual increase with progression of pregnancy, starting with early gestational stages until prepartum luteolysis when it was highest $(P<0.01$ and $P<0.05$ when compared with post-implantation) (Fig. 4).

\section{Localization of ECM proteins in the canine uterus and placenta}

Localization and distribution patterns of COL1, COL3, COL4, FN1, ECM1, LAMA2, Cx26, Cx43, TIMP2 and TIMP4 were investigated at the protein level by applying IHC. All experimental groups were examined. A summary of the findings is presented descriptively in Fig. 5. 
COL1 and COL3 were detectable in all maternal and fetal stromal compartments and in myometrium (Fig. 6 and Supplementary Figure 1, see section on supplementary data given at the end of this article, respectively). While at all compared stages of pregnancy (including non-pregnant controls at days 10-12), COL1 staining appeared to be evenly distributed, the intensity of COL3 was generally weaker compared with COL1.

COL4 was clearly detectable throughout gestation and was targeted to the basal lamina of blood vessels (Supplementary Figure 2D and G) in all compartments. Additionally, COL4 was detected in the myometrium of all groups with staining intensity varying, however, individually (Supplementary Figure 2B, F and I).

ECM1 was weakly detectable in luminal epithelium in the non-pregnant group (in one sample it was below the detection limit) (Fig. 7A and B). In early pregnancy, strong signals were detectable in luminal epithelium and in superficial and deep glands (Fig. 7C and D). During mid-gestation and at prepartum luteolysis (Fig. 7E and H), it was only weakly detectable in the glandular epithelium of the superficial glands. At prepartum luteolysis, ECM1 was abundantly present in the connective tissue layer separating superficial glands from deep glands (Fig. 7H). Following implantation (shown at mid-gestation) (Fig. 7F) and at prepartum luteolysis (Fig. 7l), signals were detectable in glandular epithelium of deep glands. Placental localization of ECM1 was in cytotrophoblast (shown at mid-gestation and prepartum luteolysis) (Fig. 7G and J).

Uterine endometrial expression of $\mathrm{Cx} 43$ was localized predominantly in epithelial and myometrial

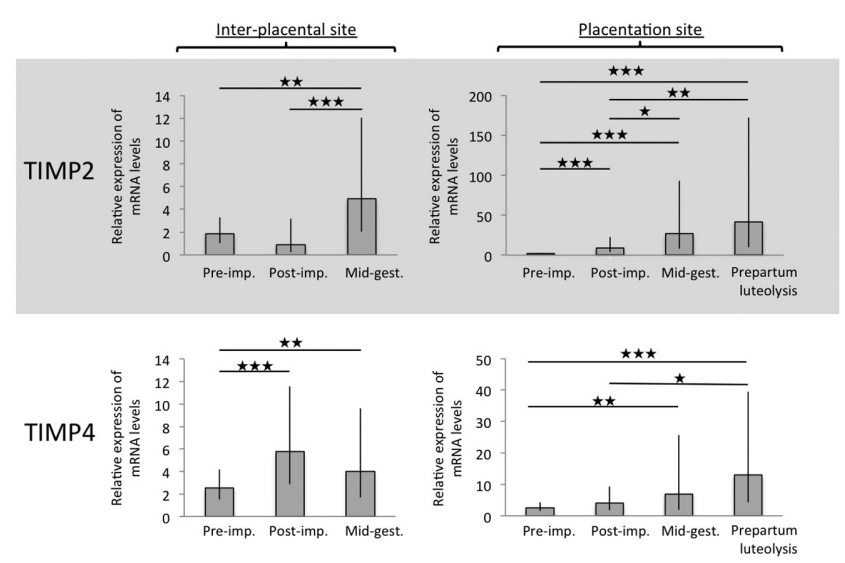

Figure 4 Expression of tissue inhibitor of metalloproteinase (TIMP) 2 and -4 as determined by Real-Time (TaqMan) PCR in canine uterus during different times of gestation. Two comparisons are presented for each gene: First, the pre-implantation (pre-imp.) stage was compared to the inter-placental sites during post-implantation (post-imp.) and mid-gestation (mid-gest.), and next to the utero-placental

compartments (placentation sites) of post-implantation (post-imp.), mid-gestation (mid-gest.) and prepartum luteolysis. Asterisks differ at $\star P<0.05, \star \star P<0.01, \star \star \star P<0.001$. Numerical data are presented as geometric means $\mathrm{Xg} \pm$ geometric standard deviation (S.D.). compartments (Fig. 8). The luminal epithelium (Fig. 8A and $\mathrm{C}$ ) and the epithelial cells of superficial and deep glands (Fig. 8A, B, C, D, E, F, H and I) stained strongly for Cx43. Additionally, Cx43 was present in the tunica intima of maternal blood vessels in all samples. In placenta (Fig. 8G and J), Cx43 was diffusely present in cytotrophoblast and syncytiotrophoblast and decidual cells. The strongest placental signals were found in the tunica intima of blood vessels (Fig. 8G and J).

Regarding TIMP2, it was only weakly expressed in the non-pregnant uterus (sometimes below detection limits) (Fig. 9A and B). In contrast, in the early pregnant uterus, at days 10-12 (prior to attachment), its expression was clearly detectable in the luminal epithelium, and superficial and deep glands (Fig. 9C and D). Myometrial signals were weak in both groups (Fig. 9B and D). Following implantation (shown at mid-gestation), endometrial TIMP2 was detectable in epithelial compartments of superficial and deep uterine glands (Fig. 9E and F); stromal compartments of the connective tissue layer appeared only weakly stained (Fig. 9E). At prepartum luteolysis, uterine TIMP2 signals were weaker in the epithelium of superficial glands (Fig. 9H). However, strong staining was observed in the connective tissue layer separating the superficial from deep glands (Fig. 9H). Myometrial signals were weak (Fig. 9F and I). Placental TIMP2 at mid-gestation was distributed ubiquitously and was found in cytotrophoblast and syncytiotrophoblast, in decidual cells and in vascular endothelial cells (tunica intima) (Fig. 9G). During prepartum luteolysis, placental expression was predominantly found in endothelial cells of maternal vessels (Fig. 9J). Sporadic nuclear staining was detected in the nuclei of myocytes, which did not allow further interpretation.

Compared with TIMP2, TIMP4 appeared to stain generally more weakly in all experimental groups and tissue compartments. Although weakly represented, uterine expression was localized in the luminal epithelium (Fig. 10A and C). Somewhat stronger staining was found in superficial and deep glands (Fig. 10A, B, C, D and F). Stronger TIMP4 signals were found during prepartum luteolysis in the connective tissue layer separating superficial from deep glands (Fig. 10H). It also appeared to be induced in deep uterine glands (Fig. 10I).

Within Ut-PI compartments, placental TIMP4 was found in cytotrophoblast (shown at mid-gestation and during prepartum luteolysis; Fig. 10G and J). For Supplementary Figure 3, consecutive cross-sections of Ut-PI compartment were prepared during prepartum luteolysis and were stained with either vimentin (VIM; Supplementary Figure 3C), pan-cytokeratin (pan-CYT; Supplementary Figure 3D), TIMP2 or TIMP4, allowing better differentiation between cellular tissue compartments stained by particular antibodies. In particular, localization patterns of both 


\begin{tabular}{|c|c|c|c|c|c|c|c|c|c|c|c|}
\hline & COL1 & COL3 & COL4 & FN1 & ECM1 & LAMA2 & Cx26 & Cx43 & TIMP2 & TIMP4 & aSMA \\
\hline \multicolumn{12}{|l|}{$\begin{array}{l}\text { NON-PREGNANT } \\
\text { ENDOMETRIUM }\end{array}$} \\
\hline Luminal epithelium & - & - & - & + & + & + & $+/-$ & + & $+/-$ & $+/-$ & - \\
\hline Stroma & + & + & - & + & - & + & - & - & - & - & + \\
\hline Glandular epithelium & - & - & - & + & - & + & $+/-$ & + & $+/-$ & + & - \\
\hline Blood vessels & - & - & + & - & - & + & - & + & + & - & ++ \\
\hline \multicolumn{12}{|l|}{ MYOMETRIUM } \\
\hline Smooth muscle cells & - & - & - & - & - & - & + & + & $+/-$ & - & ++ \\
\hline Stroma & + & + & + & + & - & + & - & - & + & - & - \\
\hline Blood vessels & - & - & + & - & - & + & - & + & + & - & ++ \\
\hline \multicolumn{12}{|l|}{$\begin{array}{l}\text { PRE-ATTACHMENT } \\
\text { ENDOMETRIUM }\end{array}$} \\
\hline Luminal epithelium & - & - & - & + & ++ & + & + & + & ++ & $+/-$ & - \\
\hline Stroma & + & + & - & + & - & + & - & - & - & - & - \\
\hline Glandular epithelium & - & - & - & + & + & + & + & + & ++ & + & - \\
\hline Blood vessels & - & - & + & - & - & + & - & + & + & - & + \\
\hline \multicolumn{12}{|l|}{ MYOMETRIUM } \\
\hline Smooth muscle cells & - & - & - & - & - & + & + & + & + & - & + \\
\hline Stroma & + & + & $+/-$ & + & - & + & - & - & + & - & - \\
\hline Blood vessels & - & - & + & - & - & + & - & + & + & - & ++ \\
\hline \multicolumn{12}{|l|}{$\begin{array}{l}\text { MID-GESTATION } \\
\text { PLACENTA }\end{array}$} \\
\hline Cytotrophoblast cells & - & - & - & + & + & - & + & $+/-$ & + & + & - \\
\hline Syncytiotrophoblast & - & - & - & + & - & - & + & $+/-$ & + & - & - \\
\hline Decidual cells & - & - & - & + & - & - & + & $+/-$ & + & - & ++ \\
\hline Blood vessels & - & - & + & + & - & + & + & ++ & + & - & + \\
\hline Stroma & + & + & - & + & - & + & - & - & - & - & - \\
\hline \multicolumn{12}{|l|}{ ENDOMETRIUM } \\
\hline Epithelium of superficial glands & - & - & - & + & + & + & ++ & + & + & $+/-$ & - \\
\hline $\begin{array}{l}\text { Connective tissue layer separating } \\
\text { superficial from deep glands }\end{array}$ & + & + & - & + & - & ++ & - & + & $+/-$ & - & - \\
\hline Epithelium of deep glands & - & - & - & + & + & + & + & + & + & + & - \\
\hline Blood vessels & - & - & + & + & - & + & $+/-$ & ++ & + & - & + \\
\hline \multicolumn{12}{|l|}{ MYOMETRIUM } \\
\hline Smooth muscel cells & - & - & - & - & - & + & + & + & + & - & + \\
\hline Blood vessels & - & - & + & - & - & + & - & + & + & - & ++ \\
\hline Stroma & + & + & + & + & - & + & - & - & + & + & - \\
\hline \multicolumn{12}{|l|}{$\begin{array}{l}\text { PREPARTUM LUTEOLYSIS } \\
\text { PLACENTA }\end{array}$} \\
\hline Cytotrophoblast cells & - & - & - & + & + & - & ++ & + & + & + & - \\
\hline Syncytiotrophoblast & - & - & - & + & - & - & + & + & + & - & - \\
\hline Decidual cells & - & - & - & + & - & - & + & + & + & - & ++ \\
\hline Blood vessels & - & - & + & + & - & + & $+/-$ & ++ & ++ & - & ++ \\
\hline Stroma & + & + & - & + & - & + & - & - & - & - & - \\
\hline \multicolumn{12}{|l|}{ ENDOMETRIUM } \\
\hline Epithelium of superficial glands & - & - & - & + & + & + & ++ & + & $+/-$ & $+/-$ & - \\
\hline $\begin{array}{l}\text { Connective tissue layer separating } \\
\text { superficial from deep glands }\end{array}$ & + & + & - & + & ++ & + & + & + & ++ & ++ & - \\
\hline Epithelium of deep glands & - & - & - & + & + & + & + & + & + & ++ & - \\
\hline Blood vessels & - & - & + & - & - & + & + & ++ & + & - & ++ \\
\hline \multicolumn{12}{|l|}{ MYOMETRIUM } \\
\hline Smooth muscel cells & - & - & - & - & - & + & + & + & + & - & + \\
\hline Blood vessels & - & - & + & - & - & + & + & + & + & - & + \\
\hline Stroma & + & + & $+/-$ & + & - & + & - & - & + & + & - \\
\hline
\end{tabular}

Figure 5 Tabular, descriptive presentation of localization patterns of extracellular matrix proteins (ECM) as determined by immunohistochemistry $(\mathrm{IHC})$ in canine uterine and placental compartments. $(-)$, not present; $(+/-)$, weakly present; $(+)$, strongly present; $(++)$, very strongly present; aSMA, alpha-smooth muscle actin; COL, collagen; Cx, connexin; ECM1, extracellular matrix protein 1; FN1, fibronectin 1; LAMA2, laminin alpha 2; TIMP, tissue inhibitor of matrix metalloproteinase. 

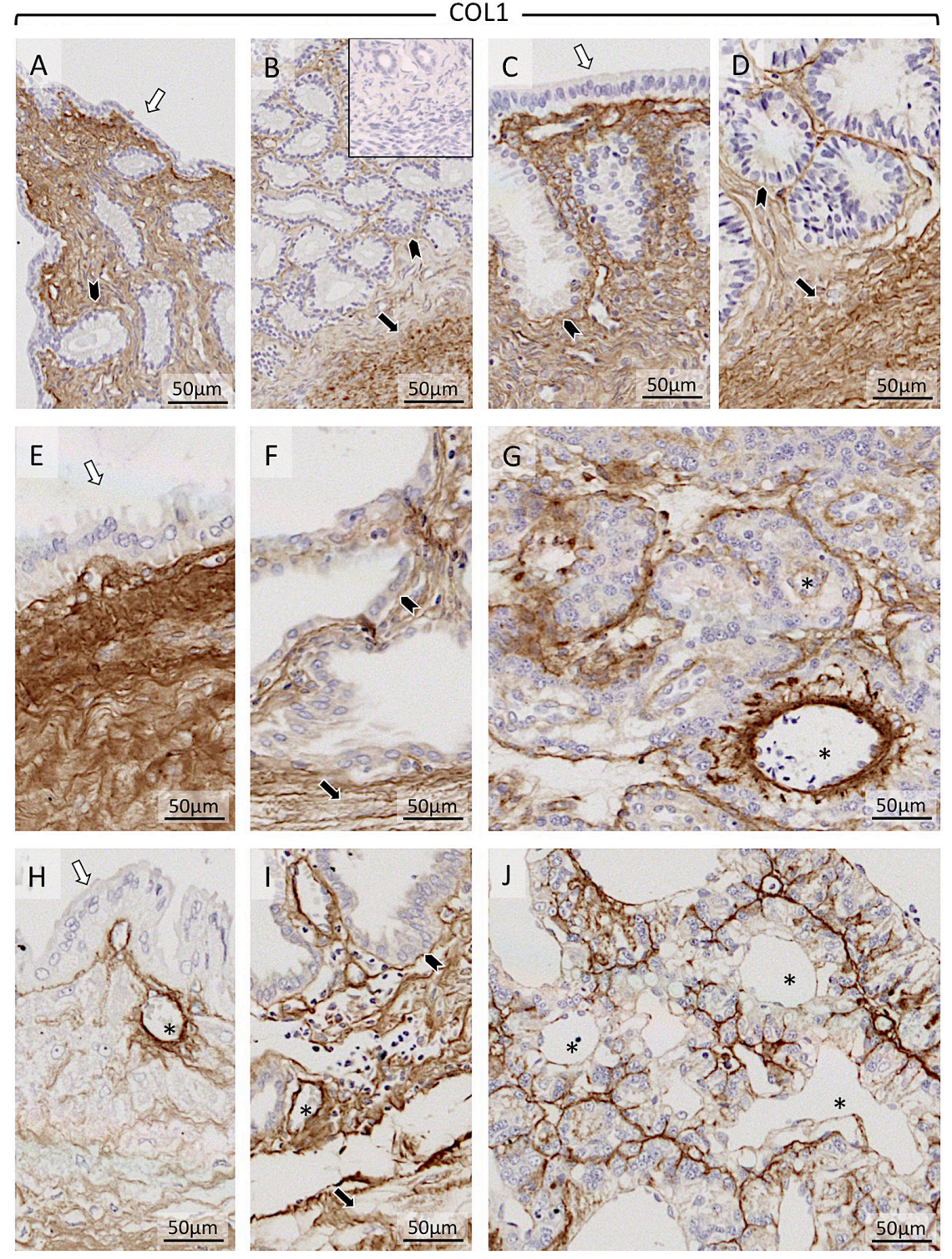

Figure 6 Representative pictures of immunohistochemical detection of collagen 1 (COL1) in the canine uterus and uteroplacental compartments (Ut-Pl) at selected time points during pregnancy: the nonpregnant canine uterus at early diestrus ( $\mathrm{A}$ and B), early pregnant (pre-implantation) canine uterus (C and D), Ut-Pl units during midgestation ( $\mathrm{E}, \mathrm{F}$ and $\mathrm{G})$, and in Ut-Pl compartments at prepartum luteolysis $(\mathrm{H}, \mathrm{I}$ and J); ( $A$ and $C$ ) luminal part of uterus with surface area; (B, D, F and I) deep glands area at the border with the myometrium; $(\mathrm{E}$ and $\mathrm{H})$ the connective tissue layer and part of the glandular area above it (superficial glands, so-called glandular chambers); (G and J) placental compartments. Non-pregnant (A and $B)$, and before implantation and placentation (C and D): open arrows = surface (luminal) epithelium; solid arrows $=$ myometrium (circular layer); solid arrowhead = glandular epithelium. After implantation and placentation (E, F, G, H, I and J): open arrows = glandular epithelium of superficial glands; solid arrows = myometrium (circular layer); solid arrowhead = glandular epithelium of deep glands; asterisk = blood vessel; Collagen 1 was clearly detectable throughout pregnancy in all stromal compartments. Before implantation and placentation, strong signals were detected in stroma and myometrium of both non-pregnant (A and $\mathrm{B}$ ) and pregnant dogs (C and D). Following implantation and placentation, strong signals were localized in the connective tissue layer (stromal area) separating superficial from deep glands ( $\mathrm{E}$ and $\mathrm{H})$ as well as in myometrial ( $\mathrm{F}$ and $\mathrm{I})$ and placental stromal ( $\mathrm{G}$ and $\mathrm{J}$ ) compartments. Inset in picture B shows a negative (isotype) control. factors within canine placenta are clearly presented, with TIMP2 targeting to vascular endothelial cells and cytotrophoblast, presenting only weak signals in syncytiotrophoblast and maternal decidual cells (Supplementary Figure 3A). Clear TIMP4 signals were localized in cytotrophoblast (Supplementary Figure 3B).

In all samples, strong signals for aSMA were found in myometrium and the media of blood vessels (Supplementary Figure 4). Additionally, in the placenta aSMA was present in decidual cells, as shown at midgestation and prepartum luteolysis (Supplementary Figure 4G and J).

FN1 was detectable throughout pregnancy. In general, stronger signals were found in epithelial than stromal compartments. The luminal epithelium of the nonpregnant group (Supplementary Figure 5A) was more strongly stained compared with the pre-attachment group (Supplementary Figure 5C). The myometrium stained weakly in all experimental groups and was below detection limits in some samples (Supplementary Figure 5B, F and I). Additionally, diffuse signals for FN1 were observed throughout all cellular placental compartments, i.e., syncytio- and cytotrophoblast, decidual cells and blood vessels (Supplementary Figure $5 \mathrm{G}$ and $\mathrm{J}$ ).

LAMA2 (Supplementary Figure 6) was clearly present in all stromal compartments and in the media of blood vessels throughout pregnancy. Additionally, it was detectable in glandular epithelial cells in all groups. In the placental part of Ut-PI compartments, LAMA2 staining was stronger in the stroma than in blood vessels (Supplementary Figure 6G and J).

Regarding Cx26, this protein was present in epithelial compartments throughout pregnancy (Supplementary 

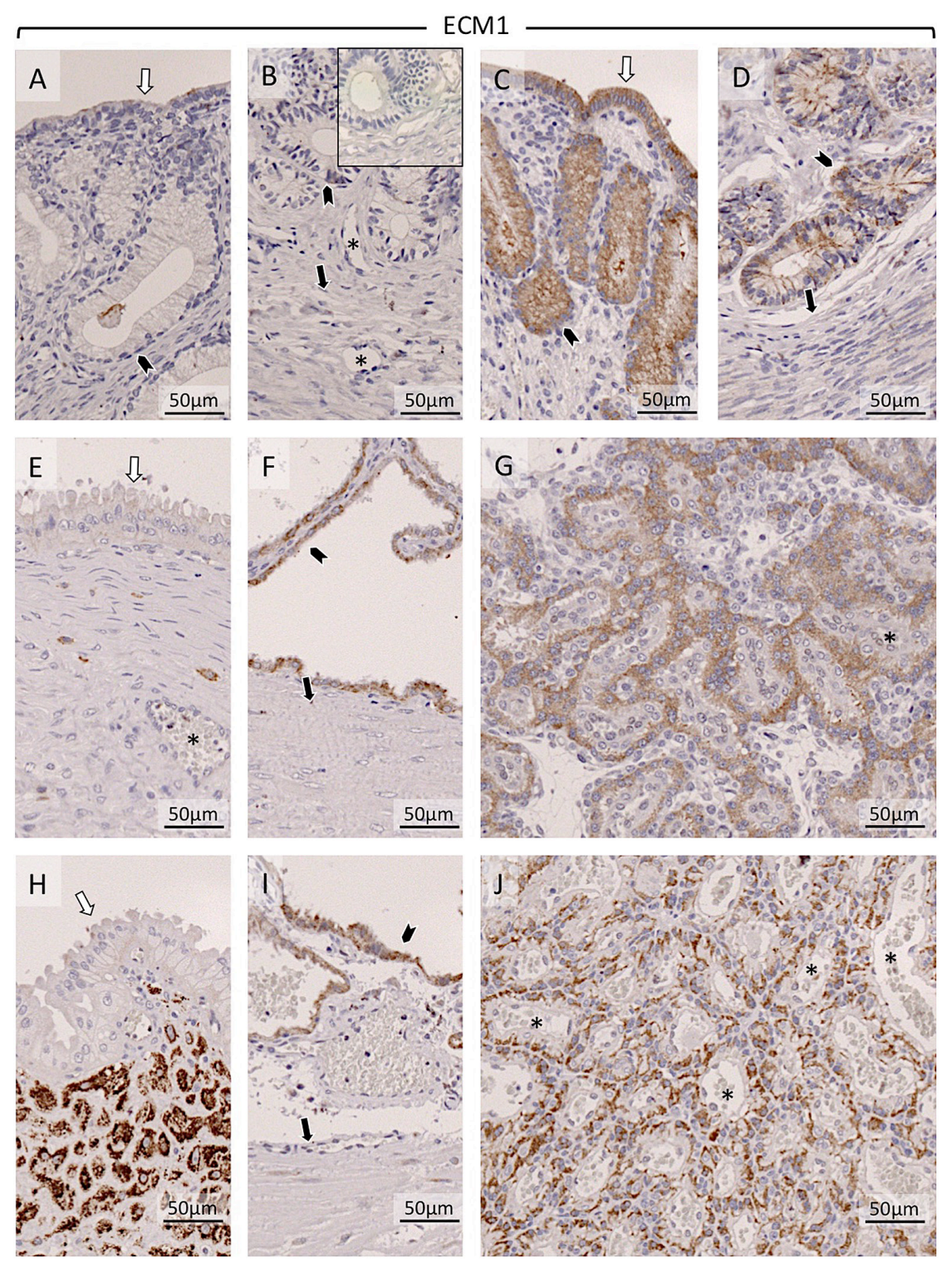

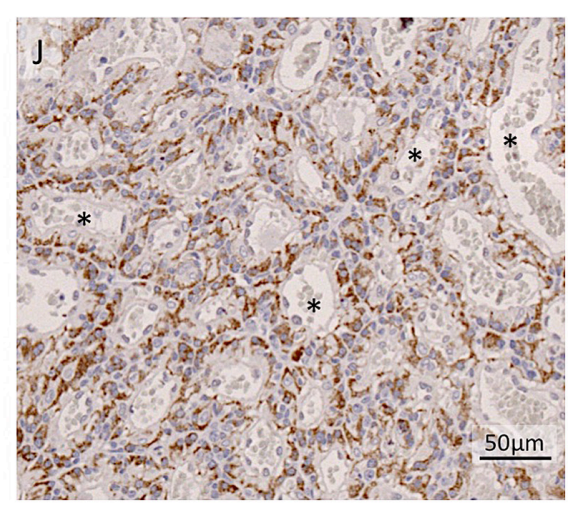

Figure 7 Representative pictures of immunohistochemical detection of extracellular matrix protein 1 (ECM1) in the canine uterus and utero-placental compartments (Ut-Pl) at selected time points during pregnancy: in the non-pregnant canine uterus at early diestrus (A and B), early pregnant (pre-implantation) canine uterus $(\mathrm{C}$ and D), Ut-PI units during mid-gestation (E, F and $\mathrm{G})$, and in Ut-PI compartments at prepartum luteolysis ( $\mathrm{H}, \mathrm{I}$ and J); (A and C) luminal part of uterus with uterine surface area; (B, D, F and I) deep glands area at the border with the myometrium; ( $\mathrm{E}$ and $\mathrm{H})$ the connective tissue layer and part of the glandular area above it (superficial glands, so-called glandular chambers); (G and J) placental compartments. Non-pregnant (A and $\mathrm{B})$, and before implantation and placentation (C andD): open arrows = surface (luminal) epithelium; solid arrows = myometrium (circular layer); solid arrowhead = glandular epithelium; asterisk=blood vessel. After implantation and placentation (E, F, G, H, I and J): open arrows = glandular epithelium of superficial glands; solid arrows = myometrium (circular layer); solid arrowhead = glandular epithelium of deep glands; asterisk = blood vessel; ECM1 was weakly detectable in luminal epithelium in the non-pregnant group (A and B). In early pregnancy, strong signals were detectable in luminal epithelium and in superficial and deep glands (C and D). During mid-gestation (E) and at prepartum luteolysis (H), ECM1 was weakly detectable in glandular epithelium of the superficial glands. At prepartum luteolysis, ECM was strongly present in the connective tissue layer separating superficial glands from deep glands $(\mathrm{H})$. In mid-gestation $(\mathrm{F})$ and at prepartum luteolysis (I), ECM1 was detectable in the glandular epithelium of deep glands. Placental localization of ECM1 was in cytotrophoblast, shown at mid-gestation (G) and prepartum luteolysis (J). Inset in picture B shows respective negative (isotype) control.
Figure 7). Generally, signals were weaker in stromal and myometrial compartments. Cx26 was also detectable in endometrial epithelial cells. Following implantation, as shown during mid-gestation and at prepartum luteolysis, this protein was strongly locally induced in the epithelial cells of glandular chambers immediately above the connective tissue layer (Supplementary Figure 7E and H). Placental Cx26 was present diffusely in cytotrophoblast and syncytiotrophoblast and in decidual cells (indicated in Supplementary Figure 6J).

\section{Discussion}

The effects of modifications of uterine ECM on canine pregnancy have not been considered for many years. Because different tissues consist of dissimilar mixed combinations of cells, which evolutionarily developed from different pedigrees, the configuration of ECM varies among tissues (Abedin \& King 2010). These ECM components are involved in the regulation of cell growth and differentiation, act as extracellular storage of hormones and are involved in the activation of signaling cascades (reviewed in Hubmacher \& Apte 2013, da Anunciacao et al. 2017). In the uterus, the major ECM components are collagens, proteoglycans, hyaluronan and glycoproteins (Leoni et al. 1990, Oliveira et al. 2015, Franczyk et al. 2017). It is worth noting that in mammals, the uterine ECM composition changes dynamically depending on the reproductive status (i.e., non-pregnant vs pregnant) (Cabrol et al. 1985, Leoni et al. 1990, Hjelm et al. 2002, Boos et al. 2003), and in some species, such as humans and cattle, 

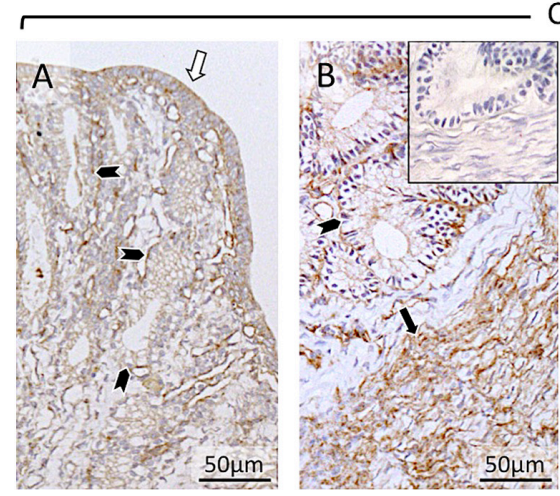

\section{$\mathrm{Cx} 43$}
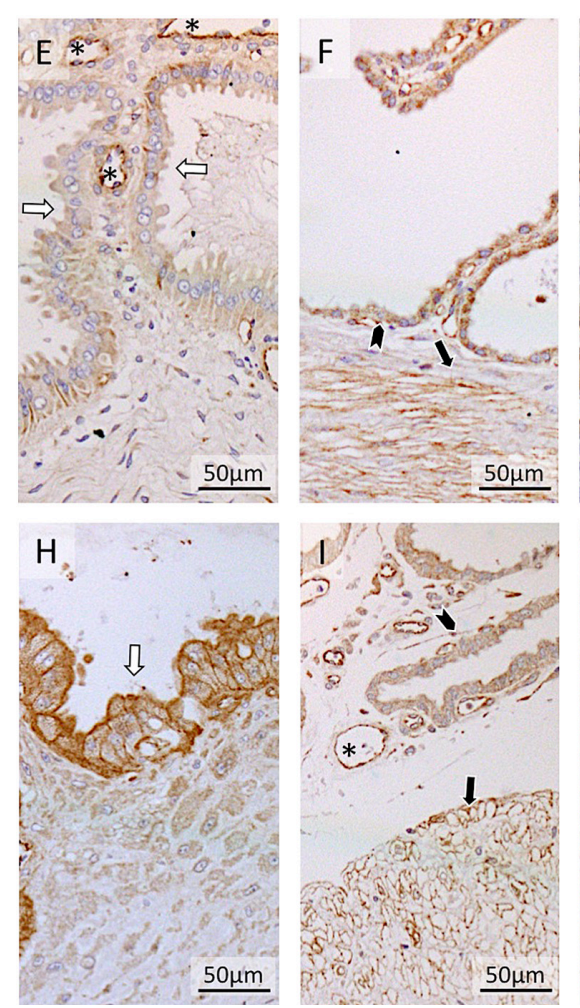
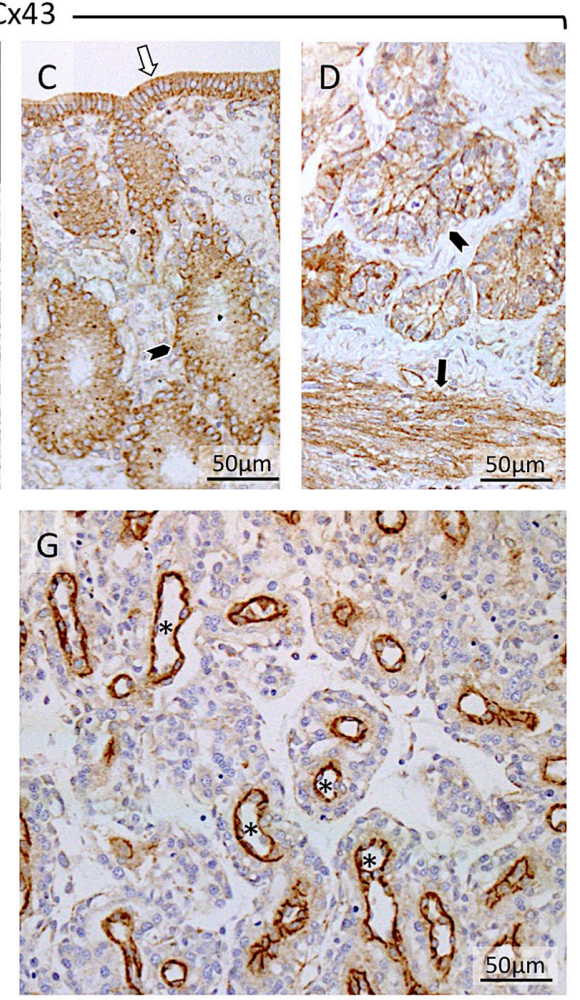

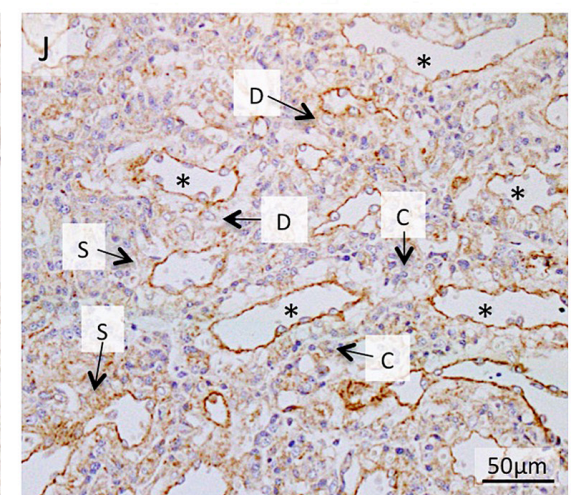

Figure 8 Representative pictures of immunohistochemical detection of cell adhesion molecule connexin 43 (Cx43) in the canine uterus and utero-placental compartments (Ut-PI) at selected time points during pregnancy: in the non-pregnant canine uterus at early diestrus (A and B), early pregnant (pre-implantation) canine uterus (C and D), Ut-PI units during mid-gestation ( $\mathrm{E}, \mathrm{F}$ and $\mathrm{G})$, and in Ut-PI compartments at prepartum luteolysis ( $\mathrm{H}, \mathrm{I}$ and $\mathrm{J})$; (A and $\mathrm{C}$ ) luminal part of uterus with uterine surface area; (B, D, F and I): deep glands area at the border with the myometrium; (E and $\mathrm{H}$ ) the connective tissue layer and part of the glandular area above it (superficial glands, so-called glandular chambers); ( $\mathrm{G}$ and $\mathrm{J}$ ) placental compartments. Non-pregnant (A and $B)$, and before implantation and placentation (C and D): open arrows = surface (luminal) epithelium; solid arrows = myometrium (circular layer); solid arrowhead = glandular epithelium. After implantation and placentation (E, F, G, H, I and J): open arrows = glandular epithelium of superficial glands; solid arrows = myometrium (circular layer); solid arrowhead = glandular epithelium of deep glands; asterisk = blood vessel; $\mathrm{D}=$ decidual cell; $\mathrm{S}=$ syncytiotrophoblast; $\mathrm{C}=$ cytotrophoblast; $\mathrm{Cx} 43$ was present in epithelial compartments and myometrial compartments. The luminal epithelium (A and C) and the epithelial cells of superficial and deep glands (A, B, C, D, E, F, H and I) stained strongly for $\mathrm{Cx} 43$. Additionally, the protein was present in tunica intima of blood vessels in all samples. Placental Cx43 localization was diffusely detected in cyto- and syncytiotophoblast and decidual cells ( $\mathrm{G}$ and $\mathrm{J})$, additionally strong signals for $\mathrm{Cx} 43$ were detected in the intima and media of placental blood vessels. Inset in picture B shows respective negative (isotype) control. the composition of the uterine ECM is cycle dependent (Boos 2000, Curry \& Osteen 2001). In fact, most details about uterine ECM modifications and functions during pregnancy are known only for humans and rodents. In these species, in early pregnancy, the uterine ECM influences trophoblast invasion (Johnson et al. 2003) and remodeling of decidua (Damsky et al. 1993, Lala \& Nandi 2016, Smith et al. 2016), while the ECM is modulated by matrix metalloproteinases (MMPs) of fetal (trophoblast) origin. As for the canine non-pregnant and pregnant uterus and placenta, the time- and organ-specific expression of MMP2 and -9 have been investigated (Beceriklisoy et al. 2007, Fellows et al. 2012, Diessler et al. 2017). Their expression patterns indicate pregnancy-associated modifications of ECM.

The present study explored the spatiotemporal expression of ECM components selected from our preceding microarray analysis (Graubner et al. 2017a), and known for their involvement in modulating uterine and placental functions in other animals, in the canine uterus and placenta throughout pregnancy. Quantitative assessment was done by qPCR, and cellular localization was investigated qualitatively by IHC. The antibodies applied herein proved unsuitable for Western blot analysis. It appears plausible that linearization of proteins by reducing agents during Western blot preparation affects the structure of target epitopes, thereby preventing antibody binding.

\section{Structural and adhesive proteins of the ECM}

Expression of the following proteins was assessed: COL1, COL3, COL4, ECM1, FN1, LAMA2 and aSMA. Freefloating embryos were previously reported to increase the uterine expression of LAMA2 (Graubner et al. 2017a). Here, the uterine adjustments during early 


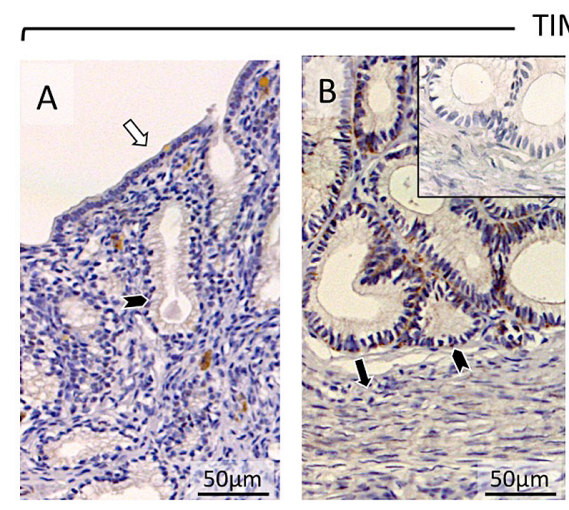

TIMP2
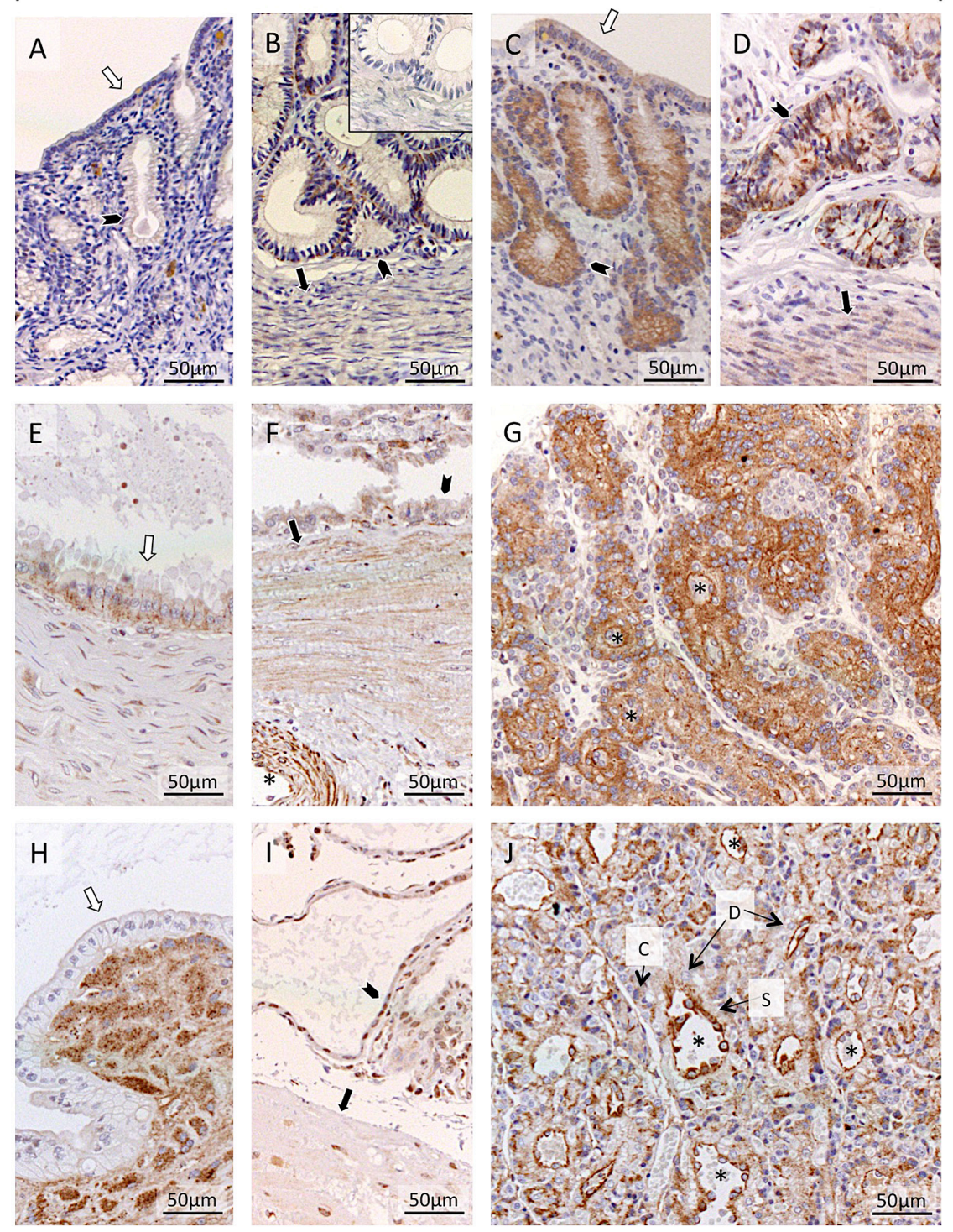

Figure 9 Representative pictures of immunohistochemical detection of tissue inhibitor of metalloproteinases 2 (TIMP2) in the canine uterus and utero-placental compartments (Ut-PI) at selected time points during pregnancy: in the non-pregnant canine uterus at early diestrus (A and B), early pregnant (pre-implantation) canine uterus (C and D), Ut-PI units during mid-gestation ( $\mathrm{E}, \mathrm{F}$ and $\mathrm{G})$, and in Ut-PI compartments at prepartum luteolysis ( $\mathrm{H}, \mathrm{I}$ and $\mathrm{J})$; (A and C) luminal part of uterus with uterine surface area; (B, D, F and I) deep glands area at the border with the myometrium; $(\mathrm{E}$ and $\mathrm{H})$ the connective tissue layer and part of the glandular area above it (superficial glands, so-called glandular chambers); ( $G$ and J) placental compartments. Non-pregnant ( $\mathrm{A}$ and B), and before implantation and placentation (C and D): open arrows = surface (luminal) epithelium; solid arrows = myometrium (circular layer); solid arrowhead = glandular epithelium. After implantation and placentation $(E, F, G, H, I$ and J): open arrows = glandular epithelium of superficial glands; solid arrows=myometrium (circular layer); solid arrowhead=glandular epithelium of deep glands; asterisk=blood vessel; $\mathrm{D}=$ decidual cell; $\mathrm{S}=$ syncytiotrophoblast; $\mathrm{C}=$ cytotrophoblast; In the non-pregnant group, TIMP2 was weakly detectable in the deep glands (B). In early pregnancy, TIMP2 was clearly detectable in luminal epithelium and epithelium of superficial (C) and deep glands (D), and myometrial compartments (D). At mid-gestation, TIMP2 was detectable in the glandular epithelium of the superficial glands $(\mathrm{E})$, but not in the stroma of the connective tissue layer separating superficial from deep glands (E). At prepartum luteolysis, TIMP2 signals appeared weaker (compared to mid-gestation) in the luminal epithelium of the superficial glands; additionally, strong signals were detected in the connective tissue layer (H). At mid-gestation (F) TIMP2 appeared in the tunica media of blood vessels in the myometrium. At mid-gestation (F) and at prepartum luteolysis (I), TIMP2 was present in the myometrium and in deep glands. In placenta at mid-gestation (G) and at prepartum luteolysis (J), TIMP2 was present in cyto- and syncytiotrophoblast, decidual cells and the intima of blood vessels. In placenta the endothelium appeared to stain strongest for TIMP2. Inset in picture B shows the respective negative (isotype) control. 

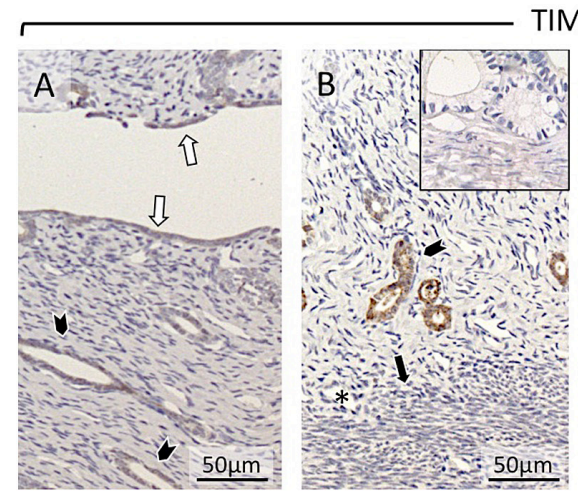

TIMP4
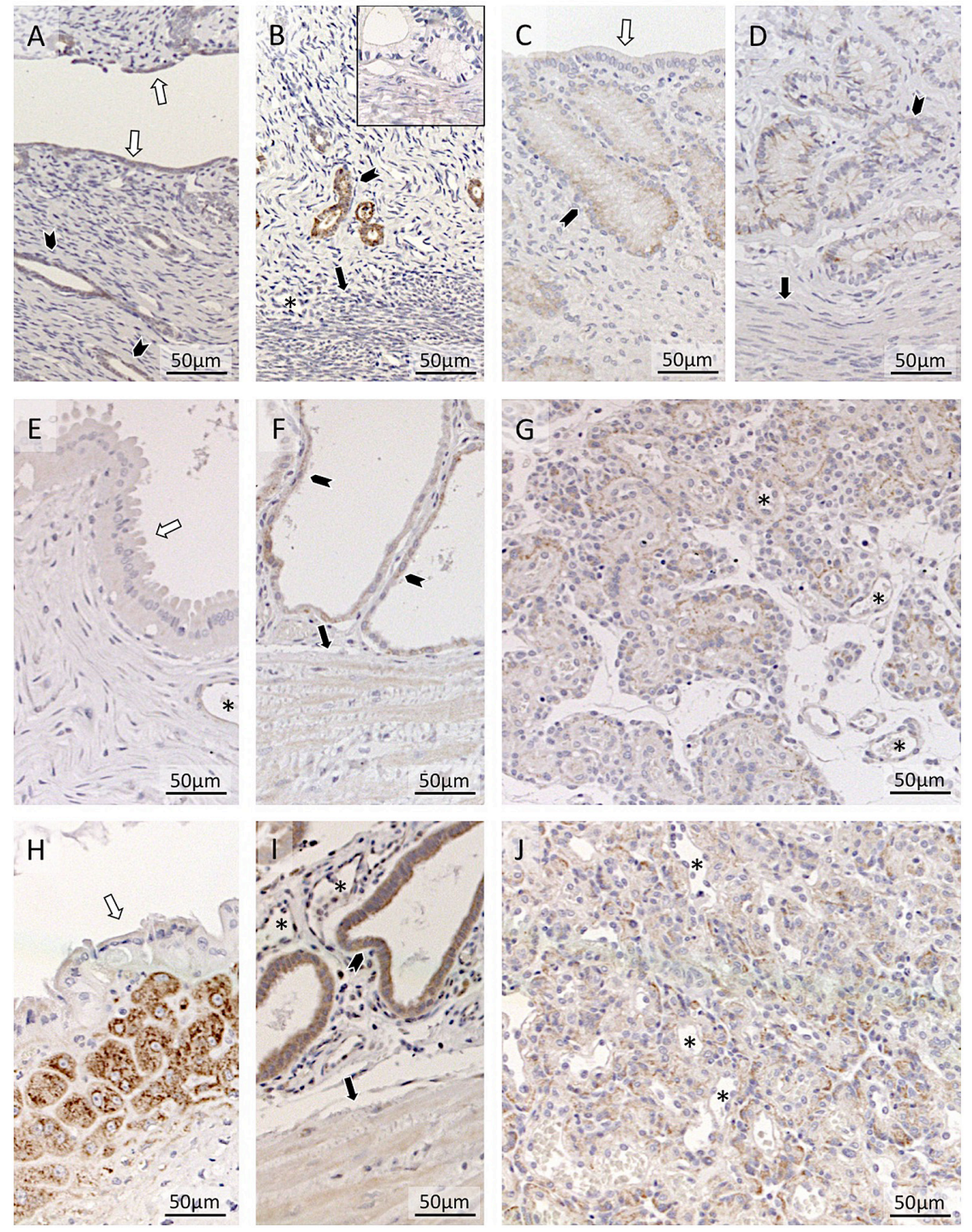

Figure 10 Representative pictures of immunohistochemical detection of tissue inhibitor of metalloproteinases 4 (TIMP4) in the canine uterus and utero-placental compartments (Ut-Pl) at selected time points during pregnancy: in the non-pregnant canine uterus at early diestrus $(A, B)$, early pregnant (pre-implantation) canine uterus $(\mathrm{C}$ and $\mathrm{D})$, Ut-Pl units during mid-gestation ( $\mathrm{E}, \mathrm{F}$ and $\mathrm{G})$, and in Ut-PI compartments at prepartum luteolysis ( $\mathrm{H}, \mathrm{I}$ and $\mathrm{J})$; ( $\mathrm{A}$ and $\mathrm{C}$ ) luminal surface area; $(B, D, F$ and $I)$ deep glands area at the border of the myometrium; ( $\mathrm{E}$ and $\mathrm{H})$ the connective tissue layer and part of the glandular area above it (superficial glands, so-called glandular chambers); ( $\mathrm{G}$ and $\mathrm{J}$ ) placental compartments. Non-pregnant (A and B), and before implantation and placentation (C and D): open arrows = surface (luminal) epithelium; solid arrows = myometrium (circular layer); solid arrowhead = glandular epithelium; asterisk = blood vessel. After implantation and placentation (E-J): open arrows = glandular epithelium of superficial glands; solid arrows $=$ myometrium (circular layer); solid arrowhead = glandular epithelium of deep glands; asterisk=blood vessel; Before trophoblast attachment (i.e. at early pregnancy), and in non-pregnant controls, TIMP4 appeared weakly present in the surface epithelium (A and C). Also superficial epithelium stained weakly throughout pregnancy. Stronger signals were seen in the epithelium of deep glands, in particular in non-pregnant dogs (B) and at mid-gestation and in the prepartum luteolysis group ( $\mathrm{F}$ and I). TIMP4 was strongly detected at prepartum luteolysis in the connective tissue layer separating superficial from deep glands $(\mathrm{H})$. In the placenta, shown at mid-gestation and prepartum luteolysis, TIMP4 was present in the cytotrophoblast ( $G$ and J). Inset in picture B shows respective negative (isotype) control. decidualization were additionally characterized by increased expression of ECM1, whereas FN1 was suppressed. None of the major COLs was affected by the presence of embryos.

Showing distinctly different localization patterns and both being affected by presence of embryos, ECM1 and LAMA2 appear to be involved in the establishment of canine pregnancy. As components of the lamina basalis, increased expression of laminins is a marker of ongoing stromal decidualization in humans (Church et al. 1997). Similarly in the dog, even if devoid of apparent morphological differentiation of the uterus, pre-implantation embryos stimulated the expression of LAMA2, predominantly in the uterine stroma. The increased ECM1 expression was abundantly localized in endometrial epithelium. In the human endometrium, its expression during implantation is further stimulated by some of the chemokines critically involved in leukocyte migration and trophoblast invasion, e.g., CX3CL1 and CCL14 (Hannan \& Salamonsen 2008). Although not yet investigated, similar functional relationships cannot be ruled out for the canine species. Further effects of ECM1 in the canine uterus might be associated with its proliferative activities. Thus, by interacting with the epidermal growth factor (EGF)-related pathways, ECM1 promotes cellular differentiation and proliferation (Lee et al. 2014). Within the canine uterus, the localization patterns of EGF receptor (EGFR) were described previously (Sagsoz et al. 2014) and reflect the localization of ECM1 presented herein. A possible functional relationship between these two entities is certainly worth attention and should be addressed in the future.

Regarding the embryo-induced suppression of the cell adhesion molecule $F N 1$, similar to the dog, its decrease during early pregnancy also occurs in rodents (Zollinger \& Smith 2017), a phenomenon that has been linked to 
the early decidualization process around the time of implantation (Grinnell et al. 1982). Moreover, reduction of FN1 expression seems to be important to prevent excessive trophoblast invasion into maternal tissues (Kaloglu \& Onarlioglu 2010). Despite the less invasive type of canine placentation compared to rodents, the FN1 decrease observed before trophoblast attachment in dogs could also possibly be linked to similar protective functions in order to control trophoblast invasion. A key mechanism in this context seems to be the cooperation of FN1 and integrin molecules in modulating trophoblast proteolytic activities (through/via) the ECM (Sutherland et al. 1993, Fazleabas et al. 1997). Interestingly, however, the canine uterine expression of several integrins (ITG) (e.g., ITGA2B, ITGB2 and ITGB3) increases in early pregnancy (Bukowska et al. 2011), while FN1 expression is diminished by the presence of embryos.

It needs to be emphasized that, in agreement with our previous findings (Graubner et al. 2017a), and in contrast to other species including humans and rodents, the above described functional changes in the canine uterus driven by the presence of embryos, take place without any morphologically visible alterations of uterine structures. The deep structural remodeling processes of the canine uterus start following implantation and placentation and are associated with increased expression of COLs (COL1, -3, and -4), ECM1 and FN1 in the uterine wall (i.e., inter-Pl). The increased expression of structural and basement membrane components, widely localized in stroma and, depending on the type of COL (e.g., COL1 and -3), in myometrium, seems to relate to the uterine growth as a natural phenomenon resulting from the development of conceptuses.

Conversely, at implantation sites, trophoblast invasion and placentation decreased the expression of two major COLs (COL1 and -3) and LAMA2. This is apparently associated with the remodeling processes and placental development, as all COLs, and in particular the most robust COL1, were clearly detectable in utero-placental stromal compartments.

Similar effects were observed in other animals displaying invasive types of placentation, e.g., in rodents, in which implantation was associated with decreased COL 1 expression at invasion sites, implying the need for COL1 suppression during remodeling events associated with embryo-induced decidualization and subsequent placentation in these animals (Clark et al. 1993).

The decrease in LAMA2 found in our study additionally indicates loss of stability of the basal lamina, and associated with it migration and differentiation of cells (Kleinman et al. 1985, Engvall et al. 1990, Aumailley 2013). This differentiates the dog from mammals with more invasive forms of placentation such as rodents and primates. Accordingly, around the time of implantation in the murine uterus, laminin is synthesized by decidual cells (Wewer et al. 1985) where it influences trophoblast migration (Zhang et al. 2000, Korgun et al. 2007). In humans also decidual cells produce laminin (Kisalus et al. 1987, Aplin et al. 1988, Haouzi et al. 2011). At later stages of human gestation, several isoforms of laminin and fibronectin are found in the basal lamina of capillaries and in the stroma and trophoblast cells of the villi (Korhonen \& Virtanen 2001). As for the dog, LAMA2 seemed to be more strongly represented in the stromal than epithelial compartments, in particular following implantation.

Besides laminin, the decidualization process in humans is marked by increased expression of aSMA (Oliver et al. 1999). This protein seems to be strongly required during pregnancy since there is a relationship between abnormal actin polymerization and pregnancy failure in humans (Montazeri et al. 2015). In dogs, aSMA is only weakly present in uterine stromal cells of nonpregnant animals and at the pre-implantation stage. However, following placentation aSMA is strongly expressed in maternal decidual cells and can be used as a cellular marker of decidual cells in the canine species. As a matter of fact, aSMA was also strongly expressed in canine decidualized uterine primary stromal cells in vitro (Kautz et al. 2015).

Following attachment and invasion of the trophoblast in dogs the girdle placenta is developing. Histologically, at the placentation site a connective tissue layer can be found that separates enlarged superficial glands (so-called glandular chambers) from deeper localized parts of the uterus. It functions as a barrier, protecting deep uterine glands and myometrium from proteolytic activity of the trophoblast. When this barrier is breached, an exaggerated invasion of trophoblast may result in SIPS (Al-Bassam et al. 1981). Clearly detectable staining of structural collagens (COL1, and -3) and basal lamina components such as LAMA2 was identified throughout pregnancy in the stroma of this connective tissue layer. Their respective mRNA levels were not modulated from post-implantation toward mid-gestation, but the major collagens, COL1 and -3, were strongly suppressed at the time of prepartum luteolysis. This may be seen as an indicator of preparation for parturition and release of the fetal membranes (placentolysis). A similar role of physiological degradation of collagens during preparation for the release of fetal membranes has been discussed for cattle (Attupuram et al. 2016). In fact, a retained placenta can be successfully treated by administration of collagenases into the umbilical artery (Eiler \& Hopkins 1993, Attupuram et al. 2016).

With regards to $F N 1$, which was generally more strongly represented in epithelial compartments, its uterine and placental expression followed the expression patterns exhibited by COLs. This leads to the assumption that the main role of $F N 1$ in the canine uterus is a bridging function between collagens and other ECM components. 
The utero-placental ECM1 expression increased with the progression of pregnancy and was highest at prepartum luteolysis. Within the placenta, ECM1 stained predominantly in cytotrophoblast, which appeared to be the major source of ECM1 in the Ut-PI compartment. This resembles results observed in humans where the importance of ECM1 during maintenance of pregnancy and fetal development is underlined by its highest expression in the placenta and fetal heart tissue but not in other organs (e.g., brain, lung, liver, kidney, pancreas or skeletal muscles) (Smits et al. 1997). In addition to the aforementioned function of ECM1 in promoting proliferation and differentiation of cells during the onset of pregnancy, at prepartum luteolysis the co-localization of ECM1 with TIMP2- and -4 in the tissue layer separating superficial from deep uterine glands strongly attracted our attention. This spatio-temporal detection is specific to prepartum luteolysis, but not at earlier stages of pregnancy. A possible implication for its function arises from in vitro studies showing ECM1-mediated reduction of MMP9 proteolytic activity in a human model (Fujimoto et al. 2006). Cumulatively, a protective role of ECM1, possibly interacting with a metalloproteinases activity-balancing system, should be considered.

\section{Connexins (Cx26 and -43)}

Connexins (Cx) build gap junction proteins, through which two cells can exchange small molecules, electrical charges and second messengers (Bruzzone et al. 1996, Kumar \& Gilula 1996, Evans \& Martin 2002). The uterine expression of $C \times 26$ and -43 has been described during the menstrual cycle in humans as well as during pregnancy in humans, rats and sheep (Winterhager et al. 1993, Grummer et al. 1994, Jahn et al. 1995, Johnson et al. 2017). Both hormonal- and embryo implantation-mediated effects were observed (Grummer et al. 2004). Successful implantation of embryos in rodents requires a complete suppression of both connexins prior to implantation (Grummer et al. 1994, 2004). At the time of implantation connexins are re-induced (Grummer et al. 1996). The importance of Cx during establishment of pregnancy has been further strengthened by their abnormal expression patterns reported in pathologies such as recurrent pregnancy loss (Laird 2006, Nair et al. 2011).

No such information was so far available regarding the canine uterus and placenta, which prompted us to investigate the expression and distribution patterns of Cx26 and -43 throughout pregnancy. The uterine expression of both $C x$ remained unaffected by the presence of free-floating embryos. The respective proteins were detectable, however, with $\mathrm{Cx} 43$ appearing more abundantly expressed than Cx26. Whereas being clearly detectable, Cx43 was more or less constantly present in the uterine wall; its increasing expression in the Ut-PI compartment followed placental development and reached its highest levels during prepartum luteolysis. It is noteworthy that, although rather ubiquitously expressed, within the placenta Cx43 mostly targeted to the maternal endothelium. This expression pattern differed strongly from that observed for Cx26, which appeared to be in agreement with observations made in other species exhibiting invasive types of placentation. Thus, the uterine and placental expression of Cx26 was strongly induced following implantation. Its expression was predominantly localized in the endometrial tissues, both at the placentation sites and at inter-PI. The prepartum luteolysis was associated with a strong decrease of the respective mRNA levels.

Regarding the possible functions of connexins within the placenta, in humans Cx43 appears indispensable for proper decidualization and uterine angiogenesis (Laws et al. 2008). Additionally, it has been shown in vitro that $C_{x} 43$ is involved in regulating differentiation of cytotrophoblast to syncytiotrophoblast and plays roles in feto-maternal exchange (Cronier et al. 2002). Based on the localization pattern of $\mathrm{Cx} 43$ described above, in the dog its involvement in uterine and placental angiogenesis also seems likely, since the strongest signals were noticed in the intima and media of placental blood vessels. The involvement of $\mathrm{Cx} 43$ during canine decidualization cannot, however, be ruled out and merits further investigations.

\section{Spatio-temporal expression of TIMP2 and TIMP4}

When discussing the development and function of the canine endotheliochorial placenta, the mechanisms controlling the invasive behavior of trophoblast need to be considered. In general, the invasive properties of trophoblast are at least in part provided by MMPs (reviewed in Goldman-Wohl \& Yagel 2002, Cohen et al. 2006). At parturition, MMPs are additionally associated with placental detachment, as shown in humans and cattle (Eiler \& Hopkins 1992, Strauss 2013, Menon et al. 2016). In dogs, MMPs are present in trophoblast cells (Beceriklisoy et al. 2007, Fellows et al. 2012, Diessler et al. 2017). Biologically active inhibitors, i.e., TIMPs, by interacting with MMPs promote cell growth, inhibit angiogenesis and reveal both anti- and pro-inflammatory effects (reviewed in Stetler-Stevenson 2008, Brew \& Nagase 2010). Although TIMP2 and TIMP4 are $50 \%$ identical in sequence, they still bear differences in specificity to MMPs (Brew \& Nagase 2010). In vitro studies with human endometrial cells have shown that TIMPs are positively associated with the decidualization process and cell migration (Graham et al. 2017). Interestingly, TIMP2 expression can be induced by P4 (Imada et al. 1994, Jo et al. 2015). We have previously shown the ability of canine embryos to increase uterine TIMP2 expression prior to implantation (Graubner et al. 2017a). During canine labor also, the placental presence of TIMP2 has been confirmed at the mRNA 
level (Fellows et al. 2012). It is assumed that interference with TIMPs functions can lead to placental retention and SIPS in dogs, or to spontaneous early pregnancy failure and placenta accreta in humans (Al-Bassam et al. 1981, Ke et al. 2006, Nissi et al. 2013).

In addition to the previously reported increase in mRNA expression of TIMP2 (Graubner et al. 2017a), here also, elevated TIMP4 expression was observed in the pre-implantation canine uterus. The stimulatory effect on gene expression was supported by IHC results in which free-floating embryos appeared to increase signals for TIMP2 in both superficial and deep uterine glands. Following implantation, a gradual increase was noted for both TIMPs (i.e. TIMP2 and -4) in uterine and placental compartments.

An important finding from our study is the strong presence of TIMP2 and -4 in the endometrial connective tissue layer separating the superficial from deep glands. In a healthy pregnancy, trophoblast invasion is stopped at this bordering protective structure. Additionally, uterine and placental TIMPs were localized around blood vessels. Thus, it is plausible to assume that both proteins are involved in the protection of maternal tissue from trophoblast invasion. Within the placenta, TIMP2 appeared more abundantly represented than TIMP4. Both factors were, however, localized in trophoblast cells, which appears to reflect an auto-/paracrine feedback loop acting within these cells, possibly controlling own proteolytic function of trophoblast and protecting the maternal tissues from excessive invasion. Although it is not known for the dog if TIMP2 and TIMP4 interact with active MMP2 and MMP9, our findings (i.e., the gradual increase of TIMP2, TIMP4 and ECM1) indicate that MMP-mediated-trophoblast invasion might be balanced by these factors. In this regard, future studies should be considered, investigating for example the expression of MMPs and their regulators within excessive trophoblast invasion leading to conditions such as SIPS.

\section{Conclusions}

In this study, we investigated the modulation of uterine and placental ECM in defined stages of canine pregnancy. Based on the presented results, it seems that the primary goal of the early embryo-maternal communication is the regulation of trophoblast invasion, and the proliferative and adhesive functions of the uterus. Following trophoblast attachment, the ECM is strongly modulated reflecting dynamic fetomaternal interactions during establishment of the canine endotheliochorial placenta.

The role of the endometrial connective tissue layer as an active, and not only physical but also a biochemical, barrier protecting maternal tissues from unrestrained trophoblast invasion, is strongly implied. This is supported by the abundant local expression of ECM components potentially actively involved in modulating the invasiveness of fetal cells.

Regulatory mechanisms involved in modulation of ECM components during establishment and maintenance of gestation modes characteristic of invasive placentation types, appear to be similar to what has been described for other mammalian species exhibiting similar or even more intense invasion by trophoblast (hemochorial placentation type). In particular, TIMPs and ECM1 appear to be plausible candidates involved in regulating the establishment and termination of pregnancy in the dog. With this, the dog could provide an interesting model for investigating placental functions in other species, e.g. in humans in whom placenta accreta appears to share several similarities with canine SIPS.

\section{Supplementary data}

This is linked to the online version of the paper at https://doi.org/10.1530/REP-17-0761.

\section{Declaration of interest}

The authors declare that there is no conflict of interest that could be perceived as prejudicing the impartiality of the research reported. All authors read and approved the final version of the manuscript.

\section{Funding}

This work was supported by the Swiss National Science Foundation (SNSF) research grant number 31003A_160251 to M P K.

\section{Author contribution statement}

F R G: involved in developing the concept of the study, experimental design, generating data, analysis and interpretation of data and writing of the manuscript. A B: knowledge transfer, critical discussion of data, editing of the manuscript. S A and I K: knowledge transfer, critical discussion of data, collection of tissue material. M P K: designed and supervised the project, involved in interpretation of the data, drafting and revising the manuscript. All authors read and approved the final manuscript.

\section{Acknowledgments}

The technical expertise and contribution of Elisabeth Högger is gratefully appreciated. Authors are grateful to Dr Barry Bavister for careful editing of the manuscript and to Prof. Dr Bernd Hoffmann, Justus-Liebig University Giessen, Germany and his team for providing the tissue material. Part of the laboratory work was performed using the logistics at the Center for Clinical Studies, Vetsuisse Faculty, University of Zurich. 


\section{References}

Abedin M \& King N 2010 Diverse evolutionary paths to cell adhesion. Trends in Cell Biology 20 734-742. (https://doi.org/10.1016/j. tcb.2010.08.002)

Al-Bassam MA, Thomson RG \& O'Donnell L 1981 Involution abnormalities in the postpartum uterus of the bitch. Veterinary Pathology 18 208-218. (https://doi.org/10.1177/030098588101800208)

Aplin JD, Charlton AK \& Ayad S 1988 An immunohistochemical study of human endometrial extracellular matrix during the menstrual cycle and first trimester of pregnancy. Cell and Tissue Research 253 231-240. (https://doi.org/10.1007/BF00221758)

Attupuram NM, Kumaresan A, Narayanan K \& Kumar H 2016 Cellular and molecular mechanisms involved in placental separation in the bovine: a review. Molecular Reproduction and Development 83 287-297. (https:// doi.org/10.1002/mrd.22635)

Aumailley M 2013 The laminin family. Cell Adhesion and Migration 7 48-55. (https://doi.org/10.4161/cam.22826)

Bazer FW 2015 History of maternal recognition of pregnancy. Advances in Anatomy, Embryology and Cell Biology 216 5-25.

Bazer FW, Wu G, Spencer TE, Johnson GA, Burghardt RC \& Bayless K 2010 Novel pathways for implantation and establishment and maintenance of pregnancy in mammals. Molecular Human Reproduction 16 135-152. (https://doi.org/10.1093/molehr/gap095)

Beceriklisoy HB, Walter I, Schafer-Somi S, Miller I, Kanca H, Izgur H \& Aslan S 2007 Matrix metalloproteinase (MMP)-2 and MMP-9 activity in the canine uterus before and during placentation. Reproduction in Domestic Animals 42 654-659. (https://doi.org/10.1111/j.14390531.2006.00838.x)

Boos A 2000 Immunohistochemical assessment of collagen types I, III, IV and $\mathrm{VI}$ in biopsy samples of the bovine uterine wall collected during the oestrous cycle. Cells Tissues Organs 167 225-238. (https://doi. org/10.1159/000016799)

Boos A, Stelljes A \& Kohtes J 2003 Collagen types I, III and IV in the placentome and interplacentomal maternal and fetal tissues in normal cows and in cattle with retention of fetal membranes. Cells Tissues Organs 174 170-183. (https://doi.org/10.1159/000072720)

Brew K \& Nagase H 2010 The tissue inhibitors of metalloproteinases (TIMPs): an ancient family with structural and functional diversity. Biochimica et Biophysica Acta 1803 55-71. (https://doi.org/10.1016/j. bbamcr.2010.01.003)

Brown JJ \& Papaioannou VE 1992 Distribution of hyaluronan in the mouse endometrium during the periimplantation period of pregnancy. Differentiation 52 61-68. (https://doi.org/10.1111/j.1432-0436.1992. tb00500.x)

Bruzzone R, White TW \& Paul DL 1996 Connections with connexins: the molecular basis of direct intercellular signaling. European Journal of Biochemistry 238 1-27. (https://doi.org/10.1111/j.1432 1033.1996.0001q.x)

Bukowska D, Kempisty B, Jackowska M, Wozna M, Antosik P, Piotrowska H \& Jaskowski JM 2011 Analysis of integrins and vascular endothelial growth factor isoforms mRNA expression in the canine uterus during perimplantation period. Polish Journal of Veterinary Sciences $\mathbf{1 4}$ 253-258.

Cabrol D, Dallot E, Cedard L \& Sureau C 1985 Pregnancy-related changes in the distribution of glycosaminoglycans in the cervix and corpus of the human uterus. European Journal of Obstetrics and Gynecology and Reproductive Biology 20 289-295. (https://doi.org/10.1016/00282243(85)90139-X)

Cha J, Sun X Dey SK 2012 Mechanisms of implantation: strategies for successful pregnancy. Nature Medicine 18 1754-1767.

Church HJ, Richards AJ \& Aplin JD 1997 Laminins in decidua, placenta and choriocarcinoma cells. Placenta 18 143-162. (https://doi.org/10.1016/ S0143-4004(97)80085-9)

Clark DE, Hurst PR, McLennan IS \& Myers DB 1993 Immunolocalization of collagen type I and laminin in the uterus on days 5 to 8 of embryo implantation in the rat. Anatomical Record 237 8-20. (https://doi. org/10.1002/ar.1092370103)

Cohen M, Meisser A \& Bischof P 2006 Metalloproteinases and human placental invasiveness. Placenta 27 783-793. (https://doi.org/10.1016/j. placenta.2005.08.006)
Concannon PW 1993 Biology of gonadotrophin secretion in adult and prepubertal female dogs. Journal of Reproduction and Fertility Supplement 47 3-27.

Concannon PW, McCann JP \& Temple M 1989 Biology and endocrinology of ovulation, pregnancy and parturition in the dog. Journal of Reproduction and Fertility Supplement 39 3-25.

Cronier L, Defamie N, Dupays L, Theveniau-Ruissy M, Goffin F, Pointis G \& Malassine A 2002 Connexin expression and gap junctional intercellular communication in human first trimester trophoblast. Molecular Human Reproduction 8 1005-1013. (https://doi.org/10.1093/molehr/8.11.1005)

Curry TE Jr \& Osteen KG 2001 Cyclic changes in the matrix metalloproteinase system in the ovary and uterus. Biology of Reproduction 64 1285-1296. (https://doi.org/10.1095/biolreprod64.5.1285)

da Anunciacao A, Mess AM, Orechio D, Aguiar BA, Favaron PO \& Miglino MA 2017 Extracellular matrix in epitheliochorial, endotheliochorial and haemochorial placentation and its potential application for regenerative medicine. Reproduction in Domestic Animals 52 3-15. (https://doi.org/10.1111/rda.13067)

Damsky C, Sutherland A \& Fisher S 1993 Extracellular matrix 5: adhesive interactions in early mammalian embryogenesis, implantation, and placentation. FASEB Journal 7 1320-1329. (https://doi.org/10.1096/ fasebj.7.14.8224605)

Dempsey EW \& Wislocki GB 1956 Electron microscopic observations on the placenta of the cat. Journal of Biophysical and Biochemical Cytology 2 743-754. (https://doi.org/10.1083/jcb.2.6.743)

Diessler M, Ventureira M, Hernandez R, Sobarzo C, Casas L, Barbeito C \& Cebral E 2017 Differential expression and activity of matrix metalloproteinases 2 and 9 in canine early placenta. Reproduction in Domestic Animals 52 35-43. (https://doi.org/10.1111/rda.12791)

Eiler H \& Hopkins FM 1992 Bovine retained placenta: effects of collagenase and hyaluronidase on detachment of placenta. Biology of Reproduction 46 580-585. (https://doi.org/10.1095/biolreprod46.4.580)

Eiler H \& Hopkins FM 1993 Successful treatment of retained placenta with umbilical cord injections of collagenase in cows. Journal of the American Veterinary Medical Association 203 436-443.

Engvall E, Earwicker D, Haaparanta T, Ruoslahti E \& Sanes JR 1990 Distribution and isolation of four laminin variants; tissue restricted distribution of heterotrimers assembled from five different subunits. Cell Regulation 1 731-740.

Evans WH \& Martin PE 2002 Gap junctions: structure and function (review). Molecular Membrane Biology 19 121-136. (https://doi. org/10.1080/09687680210139839)

Fazleabas AT, Bell SC, Fleming S, Sun J \& Lessey BA 1997 Distribution of integrins and the extracellular matrix proteins in the baboon endometrium during the menstrual cycle and early pregnancy. Biology of Reproduction 56 348-356. (https://doi.org/10.1095/biolreprod56.2.348)

Fellows EJ, Hazzard TM \& Kutzler MA 2012 Gene expression in preterm, pre-labour and parturient canine placenta. Reproduction in Domestic Animals 47 (Supplement 6) 182-185. (https://doi.org/10.1111/ rda.12021)

Franczyk M, Lopucki M, Stachowicz N, Morawska D \& Kankofer M 2017 Extracellular matrix proteins in healthy and retained placentas, comparing hemochorial and synepitheliochorial placentas. Placenta $\mathbf{5 0}$ 19-24. (https://doi.org/10.1016/j.placenta.2016.12.014)

Fujimoto N, Terlizzi J, Aho S, Brittingham R, Fertala A, Oyama N, McGrath JA \& Uitto J 2006 Extracellular matrix protein 1 inhibits the activity of matrix metalloproteinase 9 through high-affinity protein/ protein interactions. Experimental Dermatology 15 300-307. (https:// doi.org/10.1111/j.0906-6705.2006.00409.x)

Goldman-Wohl D \& Yagel S 2002 Regulation of trophoblast invasion: from normal implantation to pre-eclampsia. Molecular and Cellular Endocrinology $187 \quad 233-238 . \quad$ (https://doi.org/10.1016/S03037207(01)00687-6)

Graham A, Holbert J \& Nothnick WB 2017 miR-181b-5p modulates cell migratory proteins, tissue inhibitor of metalloproteinase 3 , and annexin A2 during in vitro decidualization in a human endometrial stromal cell line. Reproductive Sciences 24 1264-1274. (https://doi. org/10.1177/1933719116682877)

Gram A, Buchler U, Boos A, Hoffmann B \& Kowalewski MP 2013 Biosynthesis and degradation of canine placental prostaglandins: prepartum changes in expression and function of prostaglandin F2alpha- 
synthase (PGFS, AKR1C3) and 15-hydroxyprostaglandin dehydrogenase (HPGD). Biology of Reproduction 892.

Graubner FR, Gram A, Kautz E, Bauersachs S, Aslan S, Agaoglu AR, Boos A \& Kowalewski MP 2017a Uterine responses to early pre-attachment embryos in the domestic dog and comparisons with other domestic animal species. Biology of Reproduction 97 197-216.

Graubner FR, Reichler IM, Rahman NA, Payan-Carreira R, Boos A \& Kowalewski MP 2017b Decidualization of the canine uterus: From early until late gestational in vivo morphological observations, and functional characterization of immortalized canine uterine stromal cell lines. Reproduction in Domestic Animals 52 (Supplement 2) 137-147. (https:// doi.org/10.1111/rda.12849)

Grinnell F, Head JR \& Hoffpauir J 1982 Fibronectin and cell shape in vivo: studies on the endometrium during pregnancy. Journal of Cell Biology $\mathbf{9 4}$ 597-606. (https://doi.org/10.1083/jcb.94.3.597)

Grummer R, Chwalisz K, Mulholland J, Traub O \& Winterhager E 1994 Regulation of connexin26 and connexin43 expression in rat endometrium by ovarian steroid hormones. Biology of Reproduction $\mathbf{5 1}$ 1109-1116. (https://doi.org/10.1095/biolreprod51.6.1109)

Grummer R, Reuss B \& Winterhager E 1996 Expression pattern of different gap junction connexins is related to embryo implantation. International Journal of Developmental Biology 40 361-367.

Grummer R, Hewitt SW, Traub O, Korach KS \& Winterhager E 2004 Different regulatory pathways of endometrial connexin expression: preimplantation hormonal-mediated pathway versus embryo implantation-initiated pathway. Biology of Reproduction 71 273-281. (https://doi.org/10.1095/biolreprod.103.024067)

Hannan NJ \& Salamonsen LA 2008 CX3CL1 and CCL14 regulate extracellular matrix and adhesion molecules in the trophoblast: potential roles in human embryo implantation. Biology of Reproduction $\mathbf{7 9}$ 58-65. (https://doi.org/10.1095/biolreprod.107.066480)

Haouzi D, Dechaud H, Assou S, Monzo C, de Vos J \& Hamamah S 2011 Transcriptome analysis reveals dialogues between human trophectoderm and endometrial cells during the implantation period. Human Reproduction 26 1440-1449. (https://doi.org/10.1093/humrep/ der075)

Hjelm AM, Barchan K, Malmstrom A \& Ekman-Ordeberg GE 2002 Changes of the uterine proteoglycan distribution at term pregnancy and during labour. European Journal of Obstetrics and Gynecology and Reproductive Biology 100 146-151. (https://doi.org/10.1016/S03012115(01)00476-6)

Hoffmann B, Hoveler R, Nohr B \& Hasan SH 1994 Investigations on hormonal changes around parturition in the dog and the occurrence of pregnancy-specific non-conjugated oestrogens. Experimental and Clinical Endocrinology 102 185-189. (https://doi.org/10.1055/s-0029-1211280)

Hubmacher D \& Apte SS 2013 The biology of the extracellular matrix: novel insights. Current Opinion in Rheumatology 25 65-70. (https://doi. org/10.1097/BOR.0b013e32835b137b)

Imada K, Ito A, Itoh Y, Nagase H \& Mori Y 1994 Progesterone increases the production of tissue inhibitor of metalloproteinases-2 in rabbit uterine cervical fibroblasts. FEBS Letters 341 109-112. (https://doi. org/10.1016/0014-5793(94)80250-5)

Jahn E, Classen-Linke I, Kusche M, Beier HM, Traub O, Grummer R \& Winterhager E 1995 Expression of gap junction connexins in the human endometrium throughout the menstrual cycle. Human Reproduction 10 2666-2670. (https://doi.org/10.1093/oxfordjournals. humrep.a135764)

Jo YS, Lee GS, Nam SY \& Kim SJ 2015 Progesterone inhibits leptin-induced invasiveness of BeWo cells. International Journal of Medical Sciences 12 773-779. (https://doi.org/10.7150/ijms.11610)

Johnson GA, Burghardt RC, Bazer FW \& Spencer TE 2003 Osteopontin: roles in implantation and placentation. Biology of Reproduction $\mathbf{6 9}$ 1458-1471. (https://doi.org/10.1095/biolreprod.103.020651)

Johnson ML, Redmer DA, Reynolds LP \& Grazul-Bilska AT 2017 Gap junctional connexin messenger RNA expression in the ovine uterus and placenta: effects of estradiol-17beta-treatment, early pregnancy stages, and embryo origin. Domestic Animal Endocrinology 58 104-112. (https://doi.org/10.1016/j.domaniend.2016.09.004)

Kaloglu C \& Onarlioglu B 2010 Extracellular matrix remodelling in rat endometrium during early pregnancy: the role of fibronectin and laminin. Tissue and Cell 42 301-306. (https://doi.org/10.1016/j. tice.2010.07.004)
Kautz E, Gram A, Aslan S, Ay SS, Selcuk M, Kanca H, Koldas E, Akal E, Karakas K, Findik M et al. 2014 Expression of genes involved in the embryo-maternal interaction in the early-pregnant canine uterus. Reproduction 147 703-717. (https://doi.org/10.1530/REP-13-0648)

Kautz E, de Carvalho Papa P, Reichler IM, Gram A, Boos A \& Kowalewski MP 2015 In vitro decidualisation of canine uterine stromal cells. Reproductive Biology and Endocrinology 13 85. (https://doi. org/10.1186/s12958-015-0066-4)

Ke Y, Lu JH, Yang BL, Guo HQ, Ma QY, Zhu H, Shu HM \& Li DJ 2006 [Involvement of matrix metalloproteinase-2, -9, and tissue inhibitors of metalloproteinase-1, 2 in occurrence of the accrete placenta]. Zhonghua Fu Chan Ke Za Zhi 41 311-314.

Kisalus LL, Herr JC \& Little CD 1987 Immunolocalization of extracellular matrix proteins and collagen synthesis in first-trimester human decidua. Anatomical Record 218 402-415. (https://doi.org/10.1002/ ar.1092180408)

Kleinman HK, Cannon FB, Laurie GW, Hassell JR, Aumailley M, Terranova VP, Martin GR \& DuBois-Dalcq M 1985 Biological activities of laminin. Journal of Cellular Biochemistry 27 317-325. (https://doi. org/10.1002/jcb.240270402)

Korgun ET, Cayli S, Asar M \& Demir R 2007 Distribution of laminin, vimentin and desmin in the rat uterus during initial stages of implantation. Journal of Molecular Histology 38 253-260. (https://doi.org/10.1007/ s10735-007-9095-4)

Korhonen M \& Virtanen I 2001 Immunohistochemical localization of laminin and fibronectin isoforms in human placental villi. Journal of Histochemistry and Cytochemistry 49 313-322. (https://doi. org/10.1177/002215540104900305)

Kowalewski MP 2014 Luteal regression vs prepartum luteolysis: regulatory mechanisms governing canine corpus luteum function. Reproductive Biology 14 89-102. (https://doi.org/10.1016/j.repbio.2013.11.004)

Kowalewski MP, Mason JI, Howie AF, Morley SD, Schuler G \& Hoffmann B 2006a Characterization of the canine 3beta-hydroxysteroid dehydrogenase and its expression in the corpus luteum during diestrus. Journal of Steroid Biochemistry and Molecular Biology 101 254-262. (https://doi.org/10.1016/j.jsbmb.2006.06.029)

Kowalewski MP, Schuler G, Taubert A, Engel E \& Hoffmann B 2006b Expression of cyclooxygenase 1 and 2 in the canine corpus luteum during diestrus. Theriogenology 66 1423-1430. (https://doi.org/10.1016/j. theriogenology.2006.01.039)

Kowalewski MP, Beceriklisoy HB, Aslan S, Agaoglu AR \& Hoffmann B 2009 Time related changes in luteal prostaglandin synthesis and steroidogenic capacity during pregnancy, normal and antiprogestin induced luteolysis in the bitch. Animal Reproduction Science 116 129-138. (https://doi. org/10.1016/j.anireprosci.2008.12.011)

Kowalewski MP, Beceriklisoy HB, Pfarrer C, Aslan S, Kindahl H, Kucukaslan I \& Hoffmann B 2010 Canine placenta: a source of prepartal prostaglandins during normal and antiprogestin-induced parturition. Reproduction 139 655-664. (https://doi.org/10.1530/REP-09-0140)

Kowalewski MP, Meyer A, Hoffmann B, Aslan S \& Boos A 2011 Expression and functional implications of peroxisome proliferator-activated receptor gamma (PPARgamma) in canine reproductive tissues during normal pregnancy and parturition and at antiprogestin induced abortion. Theriogenology 75 877-886. (https://doi.org/10.1016/j. theriogenology.2010.10.030)

Kumar NM \& Gilula NB 1996 The gap junction communication channel. Cell 84 381-388. (https://doi.org/10.1016/S0092-8674(00)81282-9)

Laird DW 2006 Life cycle of connexins in health and disease. Biochemical Journal 394 527-543. (https://doi.org/10.1042/BJ20051922)

Lala PK \& Nandi P 2016 Mechanisms of trophoblast migration, endometrial angiogenesis in preeclampsia: the role of decorin. Cell Adhesion and Migration 10 111-125. (https://doi.org/10.1080/19336918.2015.1106669)

Laws MJ, Taylor RN, Sidell N, DeMayo FJ, Lydon JP, Gutstein DE, Bagchi MK \& Bagchi IC 2008 Gap junction communication between uterine stromal cells plays a critical role in pregnancy-associated neovascularization and embryo survival. Development 135 2659-2668. (https://doi.org/10.1242/dev.019810)

Lee K-M, Nam K, Oh S, Lim J, Kim Y-P, Lee JW, Yu J-H, Ahn S-H, Kim SB, Noh D-Y et al. 2014 Extracellular matrix protein 1 regulates cell proliferation and trastuzumab resistance through activation of epidermal growth factor signaling. Breast Cancer Research 16 479. (https://doi. org/10.1186/s13058-014-0479-6) 
Leoni P, Carli F \& Halliday D 1990 Collagen in the pregnant and non pregnant uterus. Clinical Science 79 10P-11P.

Menon R, Bonney EA, Condon J, Mesiano S \& Taylor RN 2016 Novel concepts on pregnancy clocks and alarms: redundancy and synergy in human parturition. Human Reproduction Update 22 535-560. (https:// doi.org/10.1093/humupd/dmw022)

Montazeri M, Sanchez-Lopez JA, Caballero I, Maslehat Lay N, Elliott S, Lopez-Martin S, Yanez-Mo M \& Fazeli A 2015 Activation of Tolllike receptor 3 reduces actin polymerization and adhesion molecule expression in endometrial cells, a potential mechanism for viral-induced implantation failure. Human Reproduction 30 893-905. (https://doi. org/10.1093/humrep/deu359)

Nair RR, Jain M \& Singh K 2011 Reduced expression of gap junction gene connexin 43 in recurrent early pregnancy loss patients. Placenta 32 619-621. (https://doi.org/10.1016/j.placenta.2011.05.010)

Nissi R, Talvensaari-Mattila A, Kotila V, Niinimaki M, Jarvela I \& Turpeenniemi-Hujanen T 2013 Circulating matrix metalloproteinase MMP-9 and MMP-2/TIMP-2 complex are associated with spontaneous early pregnancy failure. Reproductive Biology and Endocrinology 112. (https://doi.org/10.1186/1477-7827-11-2)

Niswender GD, Juengel JL, Silva PJ, Rollyson MK \& McIntush EW 2000 Mechanisms controlling the function and life span of the corpus luteum. Physiological Reviews 80 1-29. (https://doi.org/10.1152/ physrev.2000.80.1.1)

Oliver C, Montes MJ, Galindo JA, Ruiz C \& Olivares EG 1999 Human decidual stromal cells express alpha-smooth muscle actin and show ultrastructural similarities with myofibroblasts. Human Reproduction $\mathbf{1 4}$ 1599-1605.

Oliveira GBd, Vale AMd, Santos ACd, Moura CEBd, Rocha HAdO \& Oliveira MFd 2015 Composition and significance of glycosaminoglycans in the uterus and placenta of mammals. Brazilian Archives of Biology and Technology 58 512-520. (https://doi.org/10.1590/S1516-8913201500281)

Paidas MJ, Krikun G, Huang SJ, Jones R, Romano M, Annunziato J \& Barnea ER 2010 A genomic and proteomic investigation of the impact of preimplantation factor on human decidual cells. American Journal of Obstetrics and Gynecology 202 459.e451-459.e458.

Sagsoz H, Liman N, Saruhan BG \& Kucukaslan I 2014 The expression of epidermal growth factor receptors and their ligands (epidermal growth factor, neuregulin, amphiregulin) in the bitch uterus during the estrus cycle. Animal Reproduction Science 147 161-179. (https://doi. org/10.1016/j.anireprosci.2014.04.005)

Seshagiri PB, Sen Roy S, Sireesha G \& Rao RP 2009 Cellular and molecular regulation of mammalian blastocyst hatching. Journal of Reproductive Immunology 83 79-84. (https://doi.org/10.1016/j.jri.2009.06.264)

Short RV 1969. Implantation and the maternal recognition of pregnancy. In Ciba Foundation Symposium on Foetal Autonomy, G EW Wolstenholme \& M O'Connor (eds) pp 2-31 London: Churchill.

Smith SD, Choudhury RH, Matos P, Horn JA, Lye SJ, Dunk CE, Aplin JD, Jones RL \& Harris LK 2016 Changes in vascular extracellular matrix composition during decidual spiral arteriole remodeling in early human pregnancy. Histology and Histopathology 31 557-571.

Smits P, Ni J, Feng P, Wauters J, Van Hul W, Boutaibi ME, Dillon PJ \& Merregaert J 1997 The human extracellular matrix gene 1 (ECM1): genomic structure, cDNA cloning, expression pattern, and chromosomal localization. Genomics 45 487-495. (https://doi.org/10.1006/geno.1997.4918)

Stetler-Stevenson WG 2008 Tissue inhibitors of metalloproteinases in cell signaling: metalloproteinase-independent biological activities. Science Signaling 1 re6.

Strauss JF 3rd 2013 Extracellular matrix dynamics and fetal membrane rupture. Reproductive Sciences 20 140-153. (https://doi. org/10.1177/1933719111424454)

Sutherland AE, Calarco PG \& Damsky CH 1993 Developmental regulation of integrin expression at the time of implantation in the mouse embryo. Development 119 1175-1186.

Vermeirsch H, Simoens P \& Lauwers H 2000 Immunohistochemical detection of the estrogen receptor-alpha and progesterone receptor in the canine pregnant uterus and placental labyrinth. Anatomical Record 260 42-50. (https://doi.org/10.1002/1097-0185(20000901)260:1<42::AIDAR50>3.0.CO;2-8)

Wewer UM, Faber M, Liotta LA \& Albrechtsen R 1985 Immunochemical and ultrastructural assessment of the nature of the pericellular basement membrane of human decidual cells. Laboratory Investigation 53 624-633.

Wewer UM, Damjanov A, Weiss J, Liotta LA \& Damjanov I 1986 Mouse endometrial stromal cells produce basement-membrane components. Differentiation 32 49-58. (https://doi.org/10.1111/j.1432-0436.1986. tb00555.x)

Winterhager E, Grummer R, Jahn E, Willecke K \& Traub O 1993 Spatial and temporal expression of connexin26 and connexin43 in rat endometrium during trophoblast invasion. Developmental Biology 157 399-409. (https://doi.org/10.1006/dbio.1993.1144)

Wislocki GB \& Dempsey EW 1946 Histochemical reactions in the placenta of the cat. American Journal of Anatomy 78 1-45. (https://doi. org/10.1002/aja.1000780102)

Zhang C, Duan E, Cao Y, Jiang G \& Zeng G 2000 Effect of 32/67 kDa laminin-binding protein antibody on mouse embryo implantation. Journal of Reproduction and Fertility 119 137-142. (https://doi. org/10.1530/reprod/119.1.137)

Zollinger AJ \& Smith ML 2017 Fibronectin, the extracellular glue. Matrix Biology 60-61 27-37. (https://doi.org/10.1016/j.matbio.2016.07.011)

Received 18 December 2017

First decision 12 January 2018

Revised manuscript received 24 January 2018

Accepted 9 February 2018 